\title{
Break Events of the Western North Pacific Summer Monsoon during 1979-2018
}

\author{
KE XU ${ }^{\mathrm{a}}$ AND RIYU LU ${ }^{\mathrm{a}, \mathrm{b}}$ \\ ${ }^{a}$ LASG, Institute of Atmospheric Physics, Chinese Academy of Sciences, Beijing, China \\ ${ }^{\mathrm{b}}$ College of Earth and Planetary Sciences, University of the Chinese Academy of Sciences, Beijing, China
}

(Manuscript received 28 May 2021, in final form 14 October 2021)

\begin{abstract}
The monsoon break is a typical phenomenon representing the monsoon's subseasonal variability, but our understanding of it is still limited for the western North Pacific (WNP) area. This study identifies all break events of the WNP summer monsoon (WNPSM) from 1979 to 2018. The statistical analysis suggests that break events occur from late June to late October and peak at the end of August. The occurrence frequency of break events decreases as the duration increases, with $74 \%$ of events persisting for 3-7 days and merely $26 \%$ lasting longer (8-15 days). During the break period, which is characterized by significant suppression of convection, there is an extensive anticyclonic anomaly in the lower troposphere, corresponding to a notable westward retreat of the monsoon trough and a southwestward shift of the subtropical high. Meanwhile, an anomalous cyclone and convergence in the upper troposphere are also conducive to inhibiting convection. The composite results indicate that both 10-25- and 30-60-day oscillations contribute to the break, with their dry phases explaining $49.6 \%$ and $37.5 \%$ of the original suppression of convection, respectively. Around the break, the phase alternation of the 10-25-day oscillation causes convection fluctuation, while the 30-60-day oscillation maintains a stable dry phase that favors the establishment and maintenance of the break. A further case-by-case diagnosis suggests that 46 (51) out of the 61 break events occur in dry phases of the 10-25-day (30-60-day) oscillation, whereas only 10 (4) events occur in wet phases, indicating that the phase of the two oscillations significantly modulates the occurrence of the monsoon break.
\end{abstract}

KEYWORDS: Monsoons; Intraseasonal variability; Atmospheric circulation

\section{Introduction}

Monsoon breaks usually refer to a temporary decrease in precipitation during the monsoon season, which has adverse effects on agriculture and socioeconomic development. The notable Indian monsoon break in 1972, for instance, resulted in a severe drought that affected $44 \%$ of the country and 25 million people suffered from famine (De et al. 2005; http://en.volupedia.org/wiki/Famine_in_India). Moreover, the convection redistribution caused by the monsoon break can change circulation at a large scale, affecting weather and climate in remote areas (Annamalai and Slingo 2001). Therefore, revealing the mechanisms of monsoon breaks helps us to better understand monsoon variability and related climate effects. However, except for the Indian monsoon break that has been studied for decades (e.g., Ramamurthy 1969; Rao 1976; Krishnan et al. 2000; Rajeevan et al. 2010; Pai et al. 2016; Singh and Bhatla 2019), breaks of other monsoons have not yet attracted extensive attention.

The western North Pacific (WNP) summer monsoon (WNPSM) is an essential component of the Asian-Pacific summer monsoon system, and its variability can considerably affect the East Asian summer monsoon (e.g., Nitta 1987; Ueda et al. 1995; LinHo and Wang 2002). In climatology, the WNPSM shows a northeastward onset and a southward retreat process, which has been widely researched (e.g., Wu and Wang 2001; Wu 2002; Wang and LinHo 2002; Wang et al. 2005; Ueda et al. 2009). The monsoon commences over the

Corresponding author: Ke Xu, xuke@mail.iap.ac.cn southwestern Philippine Sea in mid-June, when precipitation is mainly limited to the south of $10^{\circ} \mathrm{N}$. Around mid-July, the monsoon expands to the ocean east of the Mariana Islands, with the rainfall center shifting northward to between $10^{\circ}$ and $20^{\circ} \mathrm{N}$, which signifies the arrival of the mature stage of the WNPSM. After mid-September, the monsoon begins to make a progressive retreat from north to south, which finally ends in late November.

In contrast to the widespread concern about the onset and retreat processes of the WNPSM, research on monsoon breaks is much less common. In early years, Wang and Xu (1997) defined four wet-dry cycles of the climatological intraseasonal oscillation (CISO) for the Northern Hemisphere summer monsoon. They suggested that the two dry phases of the CISO that occur in mid-July and early September correspond to two major breaks of the WNPSM. LinHo and Wang (2002) also viewed the Asian-Pacific summer monsoon as an integrated system and proposed that the boreal summer monsoon is mainly composed of two monsoon outbreaks and a monsoon break in between. This monsoon break occurs in mid-July, bringing fair weather to most of the Asian-Pacific domain.

These early studies targeted a wide temporal and spatial range. In recent years, $\mathrm{Xu}$ and $\mathrm{Lu}$ (2015) gave special attention to the evolution of convection after the WNPSM enters the mature stage. They found that after the late July rain surge, there is a distinct monsoon break in early August, which is followed by a monsoon recovery in mid-August. This monsoon break is significant in climatology, featuring drastically reduced rainfall, suppressed convection, and a weakened monsoon trough. Nevertheless, they found that this monsoon 
break has notable interannual variation, deduced from the fact that the evolution of convection around early August in $30 \%(32 \%)$ of the years is in phase (out of phase) with the climatological situation (Xu et al. 2019). This large year-to-year difference implies the necessity of studying the monsoon break as individual events. On the one hand, the characteristics of monsoon break based on events should be more evident than in climatology. On the other hand, a statistical study of events helps us know more comprehensively about monsoon break diversity. Based on previous research, this study first aims to identify break events of the WNPSM annually and diagnose their statistical characteristics and related large-scale circulations. Unlike the above studies that fixed the monsoon break in a limited region (east of the Mariana Islands) and time period (approximately early August), we selected break events over all WNP areas and during the entire monsoon season. Recently, Vega et al. (2020) defined break events of the WNPSM by a wind direction index and emphasized the difference between the monsoon active and break days, but the large-scale atmospheric circulation resulting in the monsoon break was rarely discussed.

A close relationship between the monsoon break and intraseasonal oscillation (ISO) has been documented in previous studies (Krishnamurti and Ardanuy 1980; Chen and Chen 1995; Wang and Xu 1997; Annamalai and Slingo 2001; Xu and Lu 2015, 2016; Olaguera et al. 2021). Annamalai and Slingo (2001) explored two dominant intraseasonal components (quasi-biweekly and 30-60-day oscillations) associated with the active/break phases of the Indian monsoon and showed contrasting features of the two components in origin, structure, and propagation. Over the South China Sea, which is adjacent to our study area, the monsoon break is also modulated jointly by quasi-biweekly and 30-60-day oscillations (Chen and Chen 1995; Chan et al. 2002), but the relative contribution of each oscillation varies annually (Mao and Chan 2005). Over the WNP, the two components of the ISO are both active during summer (Hsu and Weng 2001; Chen and Sui 2010; Lee et al. 2013; Liu and Wang 2014; Wu and Cao 2017). $\mathrm{Xu}$ and $\mathrm{Lu}$ (2015) indicated that the quasi-biweekly oscillation, which originates in the equatorial western Pacific and propagates northwestward, plays a crucial role in forming the WNPSM break. However, this conclusion was drawn from the climatological and multiyear mean fields. Is the relationship between the monsoon break and quasi-biweekly oscillation still robust for individual events? In addition, what is the role of the 30-60-day oscillation? These questions will be addressed in this study.

In summary, this study aims to investigate the statistical characteristics of break events of the WNPSM and to reveal the relationship between breaks and ISOs. The rest of this paper is organized as follows. The data and methods are described in section 2. Section 3 introduces the criteria for selecting break events. The statistical characteristics and large-scale circulations for break events are presented in sections 4 and 5, respectively. The impacts of quasi-biweekly and 30-60-day oscillations on the monsoon break will be explored in section 6 . The final section summarizes our conclusions.

\section{Data and methodology}

Daily interpolated outgoing longwave radiation (OLR) data derived from the National Oceanic and Atmospheric Administration (NOAA) satellite (Liebmann and Smith 1996) were used as a proxy for convection. Daily horizontal winds, geopotential height, air temperature, and relative humidity at multiple levels were obtained from the National Centers for Environmental Prediction-Department of Energy (NCEP-DOE) Reanalysis 2 dataset (Kanamitsu et al. 2002). All daily data span 40 years from 1979 to 2018 and have a horizontal resolution of $2.5^{\circ} \times 2.5^{\circ}$. Daily anomalies were calculated by removing the $40-y r$ mean of that particular day from the raw data.

We used the Lanczos filter to extract components at different time scales. Specifically, 10-25-day and 30-60-day bandpass filters were applied to isolate the two dominant components of the ISO. Eight-day and 90-day low-pass filters were conducted to remove the synoptic-scale signal and obtain the low-frequency seasonal cycle, respectively. The main methods used in the present study were composite and correlation analysis, and the statistical significance of associated results was examined by Student's $t$ test. For the composite analysis, the $t$ test was performed by comparing the composite days with all 40-yr summer days during July-September, since most break days occur in these three months.

\section{Identification of monsoon break events}

Figure 1 shows the climatology of the WNPSM from June to October. The monsoon trough is located over the South China Sea in June (Fig. 1a), when the WNP is dominated by the subtropical high, which suppresses convection. Therefore, over the WNP, the band of deep convection (represented by OLR $<230 \mathrm{~W} \mathrm{~m}^{-2}$ ) is limited to the south of $10^{\circ} \mathrm{N}$, where the 8-90-day OLR variance is small. As the monsoon trough marches eastward into the WNP in July (Fig. 1b), the deep convection band expands distinctly northward to $20^{\circ} \mathrm{N}$. Simultaneously, the 8-90-day variance intensifies and displays a zonally elongated structure, greatly overlying the region of deep convection, which suggests a large intraseasonal variation in monsoon convection. In August (Fig. 1c), both monsoon convection and 8-90-day variance reach their peak intensity and spatial extent. Deep convection at this time covers almost all WNP areas $\left(0^{\circ}-25^{\circ} \mathrm{N}, 120^{\circ}-170^{\circ} \mathrm{E}\right)$, with the most intense center over $10^{\circ}-20^{\circ} \mathrm{N}$. Afterward, the monsoon trough gradually weakens, as well as the monsoon convection and the 8-90-day variance (Fig. 1d). In October (Fig. 1e), the convective center retreats to the south of $10^{\circ} \mathrm{N}$ again. This evolutionary process of the climatological WNPSM is consistent with previous studies (Wu and Wang 2001; Wang and LinHo 2002).

Given that the WNPSM spans an extensive time-space range and that the monsoon cycle varies with location, the annual monsoon period and break events are thereby identified at every single grid within the WNP domain $\left(0^{\circ}-25^{\circ} \mathrm{N}\right.$, $120^{\circ}-170^{\circ} \mathrm{E}$ ). At a particular grid, the monsoon onset and retreat dates are decided by both the 8-day low-pass OLR 
(a) Jun

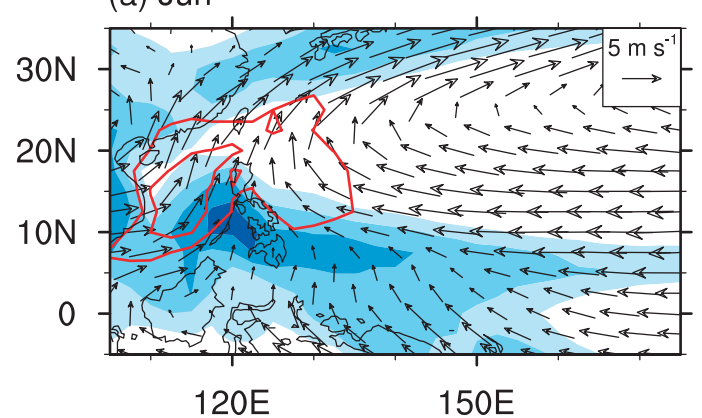

(b) Jul

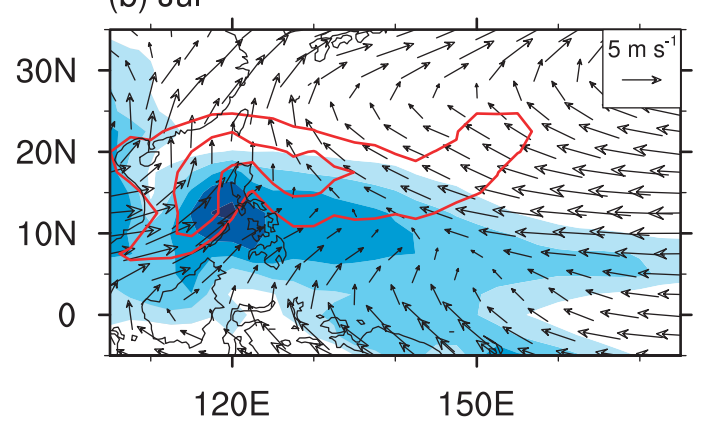

(c) Aug

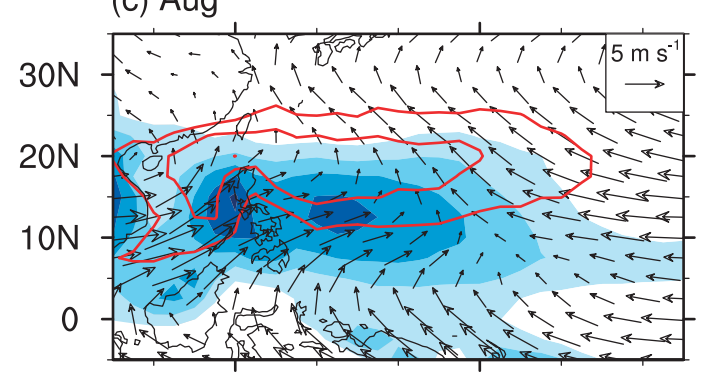

(d) Sep

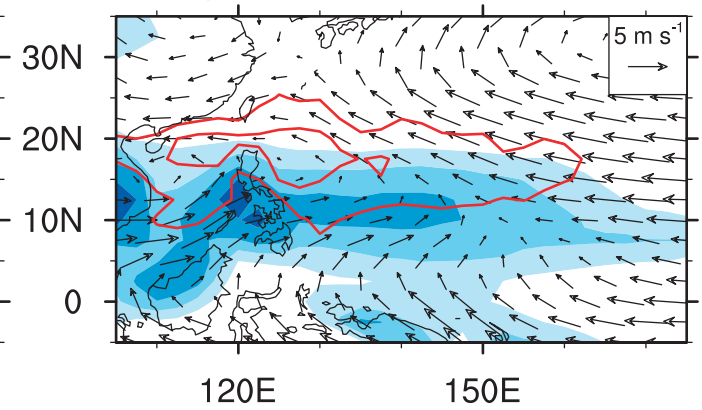

(e) Oct

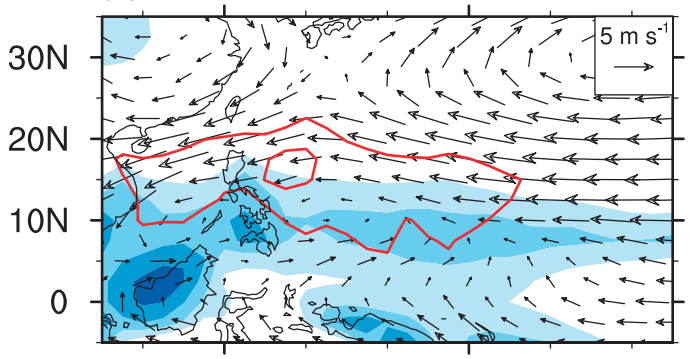

$120 \mathrm{E}$

$150 \mathrm{E}$

$150 \mathrm{E}$

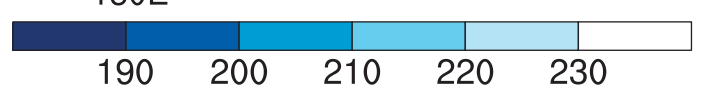

FIG. 1. Spatial distributions of the 40-yr mean OLR (colors; $\mathrm{W} \mathrm{m}^{-2}$ ), 8-90-day OLR variance (red contours; $\mathrm{W}^{2} \mathrm{~m}^{-4}$ ), and $850-\mathrm{hPa}$ wind (vectors; $\mathrm{m} \mathrm{s}^{-1}$ ) from (a) June to (e) October. The contour interval of the 8-90-day OLR variance is $300 \mathrm{~W}^{2} \mathrm{~m}^{-4}$, and only contours greater than $900 \mathrm{~W}^{2} \mathrm{~m}^{-4}$ are shown.

(removing synoptic-scale disturbances) and the seasonal cycle of OLR. Specifically, the onset (retreat) date is defined as the first day on which OLR satisfies the following two criteria:

1) The 8-day low-pass OLR transits from above to below (below to above) $230 \mathrm{~W} \mathrm{~m}^{-2}$.

2) During the wet (dry) period after this transition, the seasonal cycle also transits to below (above) $230 \mathrm{~W} \mathrm{~m}^{-2}$, signifying that the large-scale circulations and thermodynamics for the monsoon have been established (withdrawn).

The second criterion is used for the years in which the 8day low-pass OLR crosses $230 \mathrm{~W} \mathrm{~m}^{-2}$ multiple times. To confine the monsoon season in summer, the onset (retreat) should occur during May-September (after July). This definition refers to $\mathrm{Wu}$ and Wang (2000) but with some modifications, such as extending the pentad data to daily data and raising the threshold to a stricter one (from 240 to $230 \mathrm{~W} \mathrm{~m}^{-2}$ ). The threshold of $230 \mathrm{~W} \mathrm{~m}^{-2}$, which approximately corresponds to a rain rate of $8 \mathrm{~mm} \mathrm{day}^{-1}$, should be more suitable for the definition of the WNPSM according to Wang et al. (2005).

Various methods have been proposed to define monsoon breaks. Since rainfall reduction is the essential facet of monsoon breaks, many studies have directly used rainfall or OLR for definition (Krishnan et al. 2000; Gadgil and Joseph 2003; Rajeevan et al. 2010; Mandke et al. 2007). Other studies identified monsoon breaks based on circulation fields associated with rainfall reduction, such as the surface pressure distribution (Ramamurthy 1969; Rao 1976; De et al. 1998) and the 
TABLE 1. List of all break events during 1979-2018.

\begin{tabular}{|c|c|c|}
\hline Event(s) & Year & Break period(s) \\
\hline $1-2$ & 1979 & 15-18 Jul, 23 Aug-6 Sep \\
\hline 3 & 1980 & $16-21 \mathrm{Sep}$ \\
\hline $4-5$ & 1981 & 6-8 Aug, 2-9 Sep \\
\hline 6 & 1982 & $25-27$ Sep \\
\hline 7 & 1984 & 14-22 Jul \\
\hline $8-10$ & 1986 & 21-25 Jul, 26-29 Aug, 5-9 Sep \\
\hline 11 & 1987 & 29 Jul-4 Aug \\
\hline $12-13$ & 1989 & 18-30 Aug, 16-25 Sep \\
\hline $14-18$ & 1990 & 10-15 Jul, 29 Jul-8 Aug, 31 Aug-2 Sep, 19-25 Sep, 17-27 Oct \\
\hline $19-21$ & 1991 & 1-5 Aug, 27-30 Aug, 12-18 Oct \\
\hline $22-24$ & 1992 & 4-7 Jul, 7-14 Sep, 24-30 Sep \\
\hline $25-27$ & 1994 & 2-10 Aug, 27-31 Aug, 28 Sep-4 Oct \\
\hline 28 & 1996 & $25-31$ Aug \\
\hline 29 & 1997 & $1-5$ Sep \\
\hline $30-32$ & 1999 & 13-17 Aug, 22-26 Aug, 26-28 Sep \\
\hline $33-34$ & 2000 & 4-6 Aug, 14-16 Aug \\
\hline $35-36$ & 2001 & 5-8 Aug, 6-8 Sep \\
\hline 37 & 2002 & $15-17$ Jul \\
\hline 38 & 2003 & $6-8$ Oct \\
\hline $39-40$ & 2004 & 30 Jun-10 Jul, 9-12 Sep \\
\hline 41 & 2005 & 16-21 Aug \\
\hline $42-43$ & 2006 & 27 Aug-2 Sep, 6-11 Sep \\
\hline 44 & 2007 & 28 Aug-5 Sep \\
\hline 45 & 2009 & 11-19 Aug \\
\hline 46 & 2010 & $14-17$ Sep \\
\hline $47-48$ & 2011 & 21-23 Jul, 9-14 Aug \\
\hline $49-50$ & 2012 & 7-9 Aug, 2-7 Sep \\
\hline 51 & 2013 & 29 Aug-5 Sep \\
\hline $52-53$ & 2014 & 5-8 Aug, 18-22 Oct \\
\hline $54-55$ & 2015 & 19-29 Jul, 25-29 Aug \\
\hline $56-57$ & 2016 & 25-29 Aug, 31 Aug-9 Sep \\
\hline 58 & 2017 & 12-14 Aug \\
\hline $59-61$ & 2018 & 20-28 Jun, 28-30 Jul, 26-29 Aug \\
\hline
\end{tabular}

strength of the 850-hPa wind (Goswami and Ajayamohan 2001). Recently, Vega et al. (2020) defined break events during the WNPSM over a long period of time, 1949-2014, by evaluating the change in wind direction over the South China Sea and Philippine Sea.

In this study, we use OLR to determine break events, given that OLR can directly capture the large-scale convection over the WNPSM domain and has a close relationship with precipitation. Although the data length is shorter than in Vega et al. (2020), sufficient samples can be obtained for statistical analysis. Specifically, a single-grid monsoon break event is defined as a spell of at least three consecutive days in which the 8-day low-pass OLR at that grid remains higher than $230 \mathrm{~W} \mathrm{~m}^{-2}$ during the monsoon period. When the grid number for singlegrid break events exceeds $15 \%$ of the total grid number (231) and this state lasts for three days or more, it is defined as a large-scale break event. This study focuses on these largescale break events. We also tried other criteria, such as adjusting the proportion of the grid number to $10 \%$ and $20 \%$, and derived consistent conclusions. For each large-scale break event, we calculated the daily 8-day low-pass OLR averaged on those grids undergoing a break. The maximum value is defined as the event's intensity, and the corresponding day is designated as the event's peak day. Table 1 lists all 61 largescale break events obtained, including 371 break days. As shown, there are seven years in which the monsoon did not experience any break, and for the residual years the monsoon break days ranged from 3 to 38 days. This large year-to-year difference confirms the necessity of regarding the monsoon break as individual events for statistical analysis.

Figure 2 shows the spatial distribution of the $40-y r$ accumulated frequency of break days in each month. This suggests that the break is concentrated in July-September, corresponding to the mature stage of the WNPSM (Fig. 1). Few break days occur in June (Fig. 2a) because monsoon convection, limited to the south of $10^{\circ} \mathrm{N}$, shows weak intraseasonal variation (Fig. 1a). As monsoon convection and intraseasonal variation become enhanced in July (Fig. 1b), break days begin to spring up, with the highest frequency of 50 days east of the Philippines (Fig. 2b). In August (Fig. 2c), the frequency of break days reaches a peak, distributed zonally along $10^{\circ}-20^{\circ} \mathrm{N}$, and the maximum center ( $>95$ days) shifts to the east of $140^{\circ} \mathrm{E}$. This frequency distribution persists in September (Fig. 2d), except for a slight decrease in amplitude. In October (Fig. 2e), affected by the WNPSM retreat (Fig. 1e), the number of break days decreases considerably. The total break days 
(a) Jun

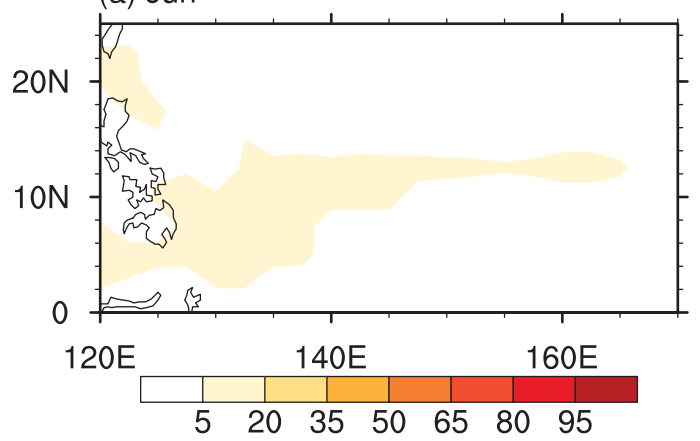

(b) Jul

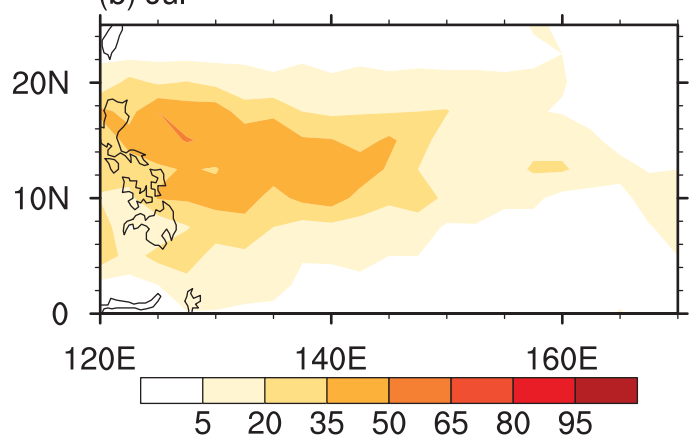

(c) Aug

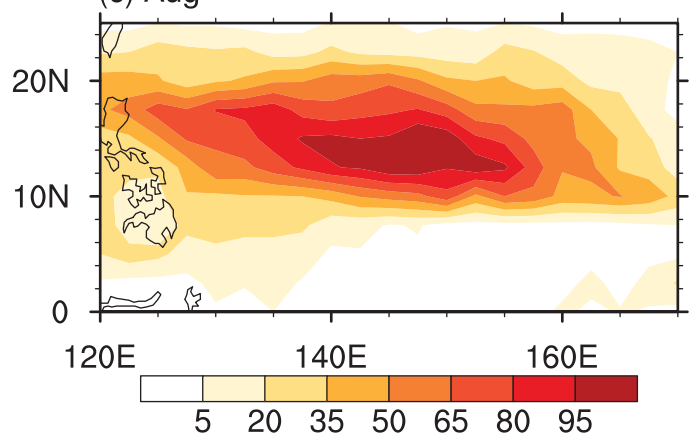

(d) Sep

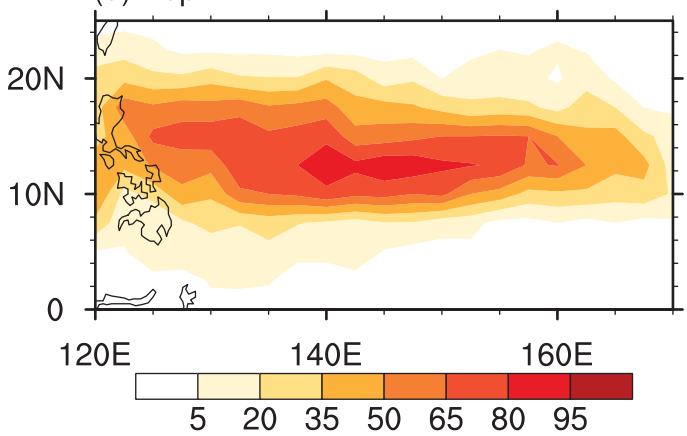

(e) Oct

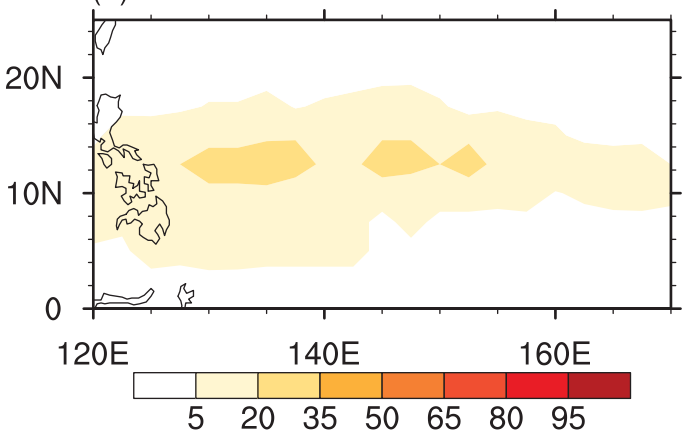

(f) Total

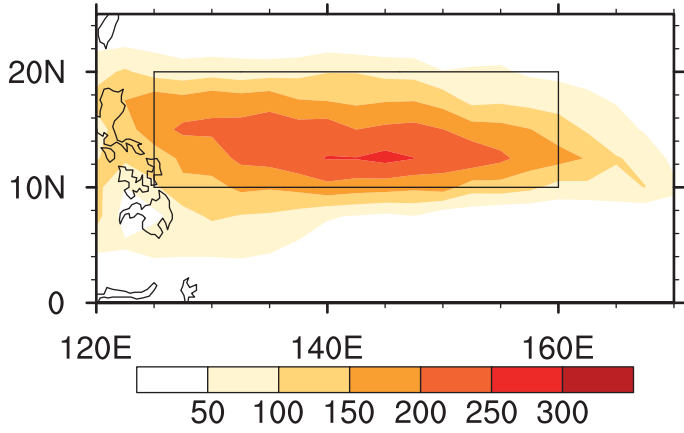

FIG. 2. Spatial distribution of the 40-yr accumulated frequency (colors; days) of break days in (a)-(e) each month and (f) total. The black rectangle in (f) denotes the key region $\left(10^{\circ}-20^{\circ} \mathrm{N}, 125^{\circ}-160^{\circ} \mathrm{E}\right)$ of the break defined in this study.

show a frequency distribution resembling those in JulySeptember (Fig. 2f). Since most break days occur in a certain area $\left(10^{\circ}-20^{\circ} \mathrm{N}, 125^{\circ}-160^{\circ} \mathrm{E}\right)$, this area is defined as the key region of the monsoon break in this study.

\section{Statistical characteristics of break events}

Based on the break events identified through the methods mentioned in the preceding section, this section will analyze their statistical characteristics. Figure 3 shows the daily evolution of the 40-yr accumulated frequency of break days, which illustrates the temporal variation of the break more clearly than the monthly results (Fig. 2). Since most break days appear in the key region (Fig. 2), the climatological areamean OLR is also shown to represent the evolution of monsoon convection. The monsoon break rarely appears in June and gradually increases from mid-July as the key region enters the monsoon season. In early August, the occurrence of the break shows a brief height of six days. After a short decline, the number of break days increases sharply at the end of August, from 2 days up to the annual peak of 12 days. In particular, the frequency remains at $>10$ days on $27-29$ August. That is, more than a quarter of the years experienced a monsoon break within the three days. Around this annual peak, frequencies higher than six days last for two weeks. This intensive occurrence of breaks may contribute to a noticeable suppression in convection in climatology, indicated by the OLR increasing from $210 \mathrm{~W} \mathrm{~m}^{-2}$ in mid-August to $225 \mathrm{~W} \mathrm{~m}^{-2}$ in early September. After mid-September, the number of break days decreases rapidly and remains low until late October. This seasonal variation in break days is somewhat different from that in Vega et al. (2020). They indicated 


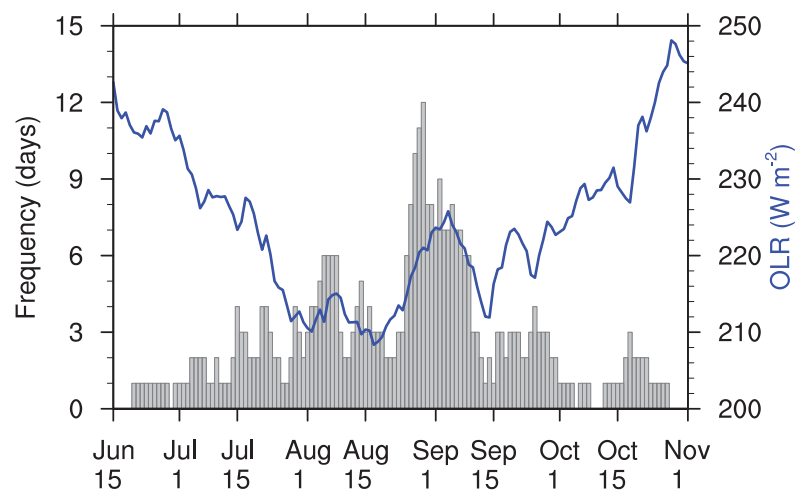

FIG. 3. Daily evolution of the 40-yr accumulated frequency of break days (bars; left $y$ axis; days). The blue line represents the climatological mean OLR averaged over the key region (right $y$ axis; $\mathrm{W} \mathrm{m}^{-2}$ ).

that the frequency of break days has a double-peak structure. The later peak at the end of August is consistent with our results, but the earlier peak in early July is not detected in Fig. 3. The primary reason for this discrepancy is that their study area included the South China Sea, where the monsoon starts as early as mid-May, while we only targeted the WNP domain east of the Philippines.

Figure 4 shows the statistical characteristics of the duration and intensity of break events. The average duration of break events is 6.1 days, and the number of events generally decreases as the duration increases (Fig. 4a). Specifically, break events lasting for 3 days are the most frequent (13 events), followed by events lasting for 5 days (10 events) and 4 days ( 9 events), and a total of $74 \%$ of events persist no longer than 1 week. However, for a duration exceeding seven days, the frequency remains less than five events. These prolonged events, ranging from 8 days up to 15 days in duration, account for merely $26 \%$ of the total events. This duration of break events is shorter than that in Vega et al. (2020). In their study, break events lasted 11-46 days, and more than half persisted 20-30 days. The difference is probably because the wind-based index used to define the break has a smaller daily fluctuation compared with the OLR-based index.

Figure $4 \mathrm{~b}$ shows the frequency distribution of break events with different intensities. The average intensity of break events is $259 \mathrm{~W} \mathrm{~m}^{-2}$. The highest frequency occurs between 255 and $260 \mathrm{~W} \mathrm{~m}^{-2}$, that is, 25-30 $\mathrm{W} \mathrm{m}^{-2}$ higher than the threshold $\left(230 \mathrm{~W} \mathrm{~m}^{-2}\right)$ used for defining monsoon convection. The occurrence frequency of break events drops considerably when the intensity is below $250 \mathrm{~W} \mathrm{~m}^{-2}$ and above $265 \mathrm{~W} \mathrm{~m}^{-2}$, which accounts for only $15 \%$ of the total. To compare the intensity of the break with that in Vega et al. (2020), we followed their analysis and examined the precipitation and vertical velocity change between active and break monsoon days (their Figs. 8 and 9). It was found that this change exhibits a similar spatial pattern but a larger amplitude than in Vega et al. (2020), which implies that the break defined in this study has a stronger intensity (not shown).

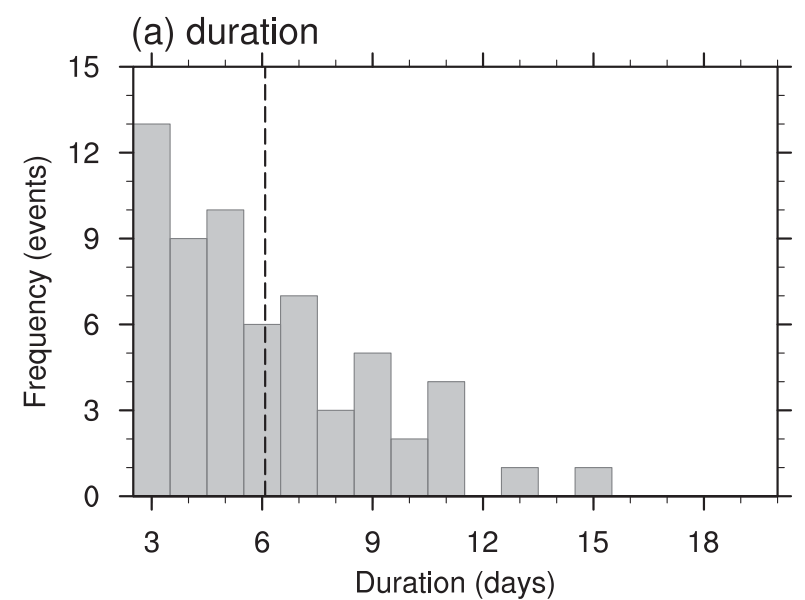

(b) intensity

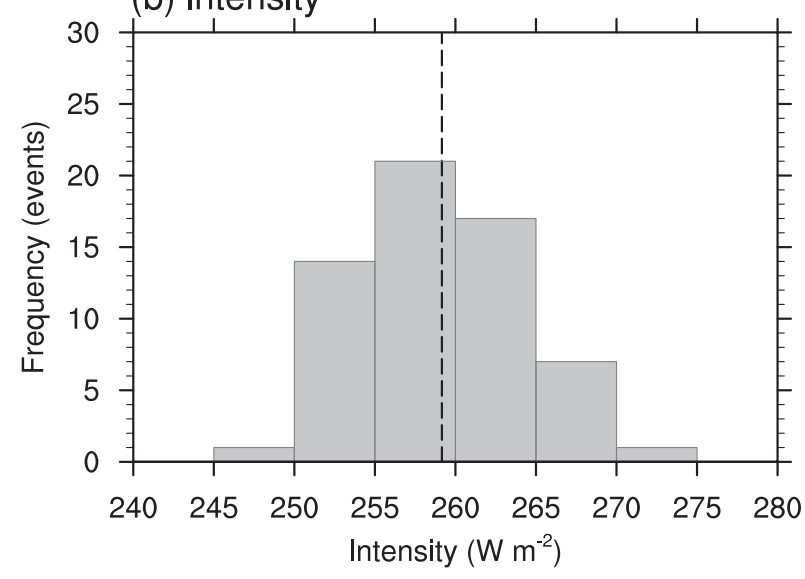

FIG. 4. Occurrence frequency of break events with different (a) durations and (b) intensities. Vertical dashed lines represent the mean duration and intensity of all break events.

\section{Large-scale circulations associated with monsoon break events}

Figure 5 shows the spatial distribution of OLR anomalies composited for break events. To manifest the change in convection around the monsoon break, we select the 7 days before (after) the onset (end) day of break events for comparison. Before the monsoon break (Fig. 5a), there are significant negative anomalies of OLR centered at the western extent of the key region, indicating anomalously enhanced convection. At this time, the region of deep convection, represented by a OLR contour of $230 \mathrm{~W} \mathrm{~m}^{-2}$, almost covers the entire key region. In addition, anomalously suppressed convection extends southeastward from the Bay of Bengal to the equatorial western Pacific. In contrast, during the monsoon break (Fig. 5b), the WNP is dominated by significant positive OLR anomalies, which display a band structure spanning from $110^{\circ}$ to $165^{\circ} \mathrm{E}$ along $10^{\circ}-20^{\circ} \mathrm{N}$. The center is located over the key region with an amplitude $>$ $30 \mathrm{~W} \mathrm{~m}^{-2}$, suggesting a considerable suppression of convection. The weakening of convection is also reflected by a noticeable southward contraction of the $230 \mathrm{~W} \mathrm{~m} \mathrm{~m}^{-2}$ 


\section{(a) Before break}

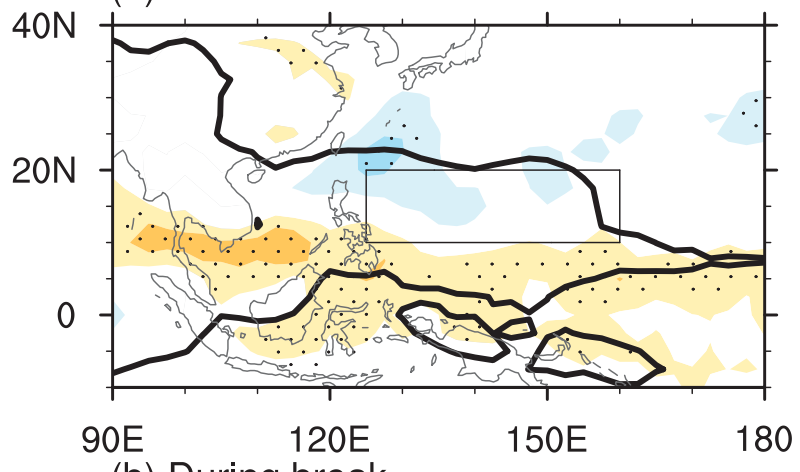

(b) During break

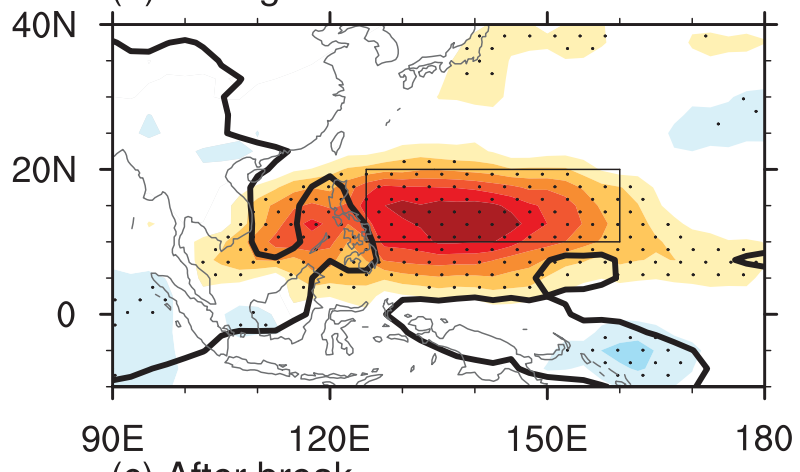

(c) After break

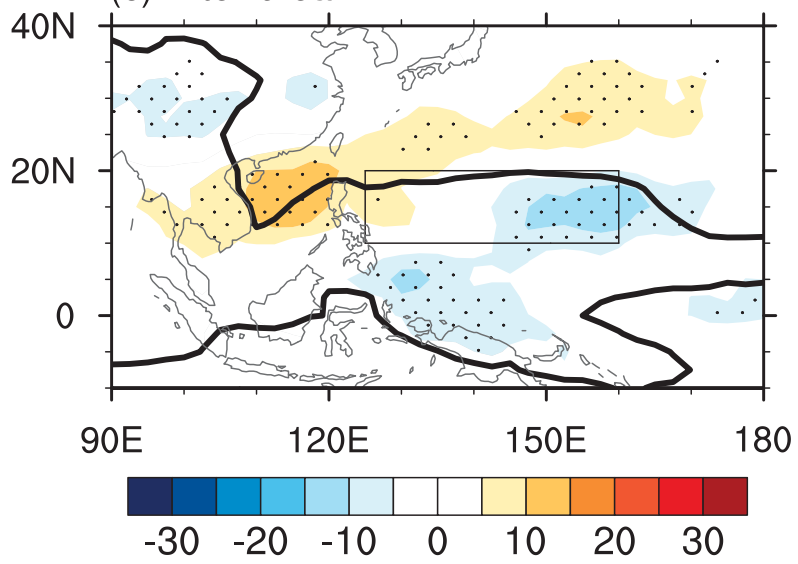

FIG. 5. Composite OLR anomalies (colors; $\mathrm{W} \mathrm{m}^{-2}$ ) averaged during (a) the 7 days before the onset day of break events, (b) the period of break events, and (c) the 7 days after the end day of break events. Stippled regions indicate the $95 \%$ confidence level based on Student's $t$ test. The thick contours denote OLR of $230 \mathrm{~W} \mathrm{~m}^{-2}$. Rectangles denote the key region of the break.

contour from $20^{\circ} \mathrm{N}$ to near the equator over the WNP. After the monsoon break (Fig. 5c), convection becomes enhanced again, indicated by the appearance of significant negative OLR anomalies and a northward expansion of the $230 \mathrm{~W} \mathrm{~m} \mathrm{~m}^{-2}$ contour. This convection variation around the monsoon break is consistent with $\mathrm{Xu}$ and $\mathrm{Lu}$ (2015), but the amplitude and spatial scope for break events are much larger than for the climatological break in their study.
The convection variation around the monsoon break is closely related to large-scale circulation changes (Fig. 6). Before the monsoon break (Fig. 6a), a cyclonic anomaly is detected at $850 \mathrm{hPa}$, corresponding to enhanced convection (Fig. 5a). At this stage, the monsoon trough stretches from the northern South China Sea to the Philippine Sea, and the ridge of the western Pacific subtropical high (WPSH) is located at $\sim 30^{\circ} \mathrm{N}$. In contrast, during the break (Fig. $6 \mathrm{~b}$ ), an extensive anticyclonic anomaly dominates the WNP, with its center to the northwest of the suppressed convection, suggesting a Rossby wave response to the reduced diabatic heating (Gill 1980). The anomalous northeasterly and divergence associated with this anomalous anticyclone, in turn, reduce the inflow of moisture over the key region and further suppress convection. Therefore, the intense weakening of convection during the break results from positive feedback via convection-circulation interactions. Corresponding to this anomalous anticyclone, the monsoon trough retreats westward to the South China Sea, while the WPSH shifts remarkably southwestward and covers a large extent of the key region, establishing a large-scale background disadvantage for convection development. After the break (Fig. 6c), a weak cyclonic anomaly occurs over the key region, accompanied by the eastward extension of the monsoon trough and northward lift of the subtropical ridge, thereby enhancing convection again.

The circulation anomalies at $200 \mathrm{hPa}$ (Figs. 6d-f) tend to exhibit an opposite pattern to that at $850 \mathrm{hPa}$. Before the break (Fig. 6d), a weak anomalous anticyclone and divergence are observed over the WNP. In contrast, during the break (Fig. 6e), the circulation anomalies exhibit a cyclone with significant convergence over the key region. The intense convergence in the upper troposphere, which is conducive to suppressing convection, seems to be associated with the strong northward cross-equatorial flows along $100^{\circ}-150^{\circ} \mathrm{E}$. It is noted that the structure of the upper-level cyclonic anomaly is not as well organized as the anticyclonic anomaly in the lower troposphere. This is because the simple Sverdrup balance of Gill's model (Gill 1980) is unsatisfactory in the upper troposphere, where nonlinear factors play a role that cannot be neglected (Sardeshmukh and Hoskins 1985). After the break (Fig. 6f), the cyclonic anomaly weakens and shifts northwestward.

The above characteristics of convection and circulation anomalies around the break (Figs. 5 and 6) are basically consistent with those in Vega et al. (2020). This consistency between the OLR-based and wind-based break events confirms that the monsoon break features tight convectioncirculation coupling over the WNP region.

\section{Relationship between break events and ISOs}

The monsoon break essentially reflects a subseasonal variation in the monsoon. As shown in Fig. 5, anomalously enhanced convection occurs before and after the monsoon break. This fluctuation in convection implies that the ISO may play a role in inducing the monsoon break. Therefore, 


\section{$850 \mathrm{hPa}$}

(a) Before break

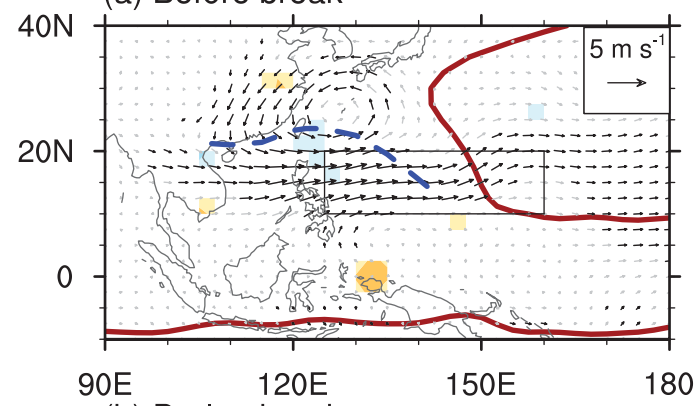

(b) During break

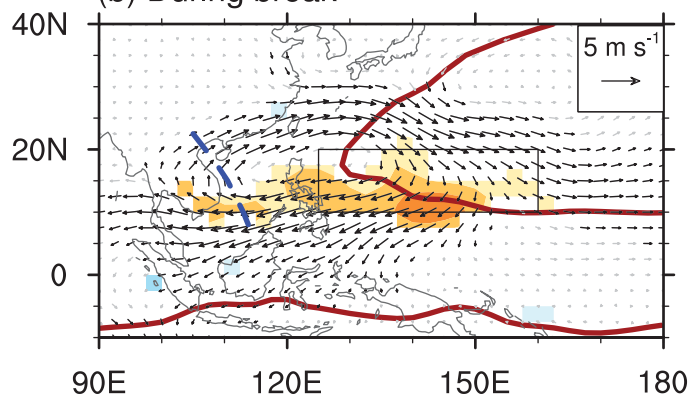

(c) After break

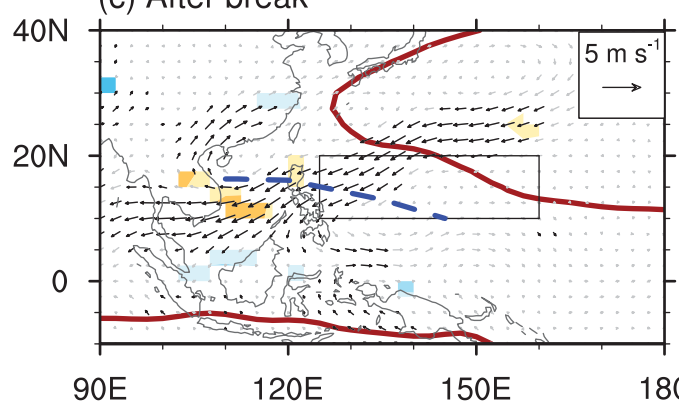

(d) Before break

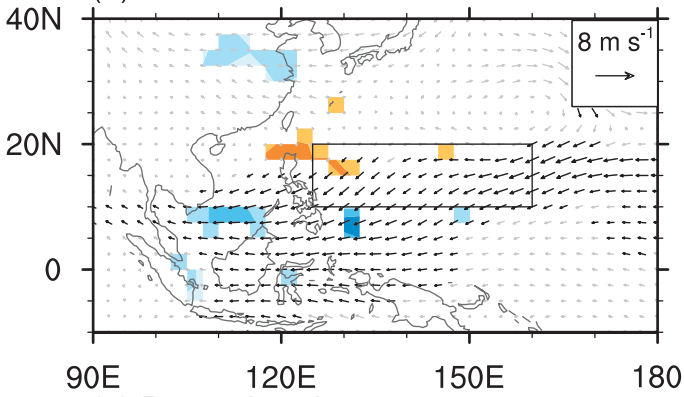

(e) During break

\section{$200 \mathrm{hPa}$}

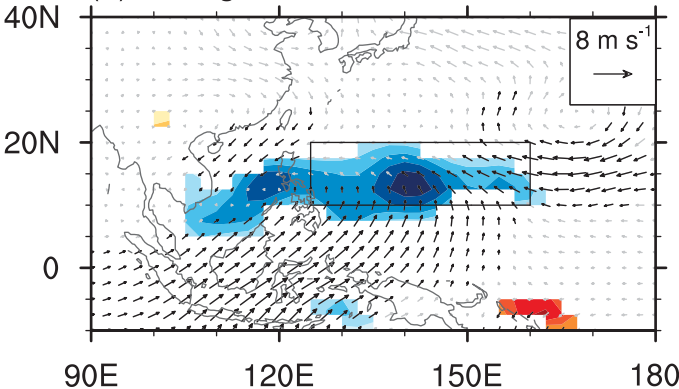

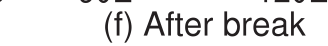

$40 \mathrm{~N}$

(f) After break
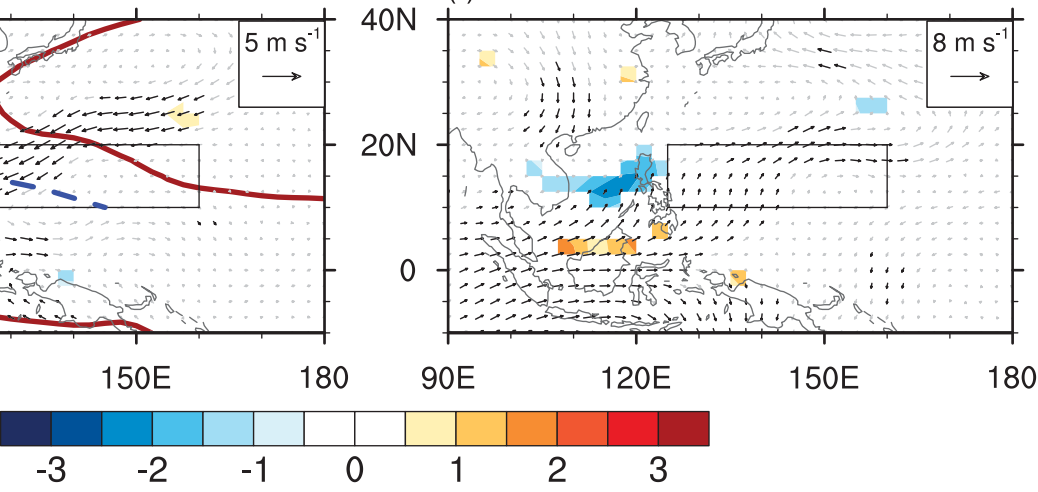

FIG. 6. As in Fig. 5, but for the anomalies of wind (vectors; $\mathrm{m} \mathrm{s}^{-1}$ ) and divergence (colors; $10^{-6} \mathrm{~s}^{-1}$ ) at (a)-(c) 850 and (d)-(f) $200 \mathrm{hPa}$. Black (gray) vectors indicate wind anomalies higher (lower) than the $95 \%$ confidence level based on Student's $t$ test. Only the divergence anomalies significant at the 95\% confidence level are shown. In (a)-(c), the brown contours represent 1510 gpm of geopotential height, which depicts the domain of the western Pacific subtropical high, and the blue dashed lines denote the locations of the monsoon trough. Rectangles denote the key region of the break.

this section will examine the impacts of the two dominant intraseasonal modes (10-25- and 30-60-day oscillations) on break events. The peak day of each break event is designated day 0 , and a composite analysis was constructed concerning this day. The negative and positive days represent the days before and after the peak day, respectively.

Given that most break events occur in the key region, the area-mean OLR anomalies are used to quantitatively diagnose the convection evolution at multiple time scales associated with the monsoon break (Fig. 7). For the original OLR anomaly (black line), enhanced convection is detected both before and after the break, consistent with the results in
Fig. 5. The OLR anomaly turns positive on day -5 , reaches the highest on days -1 to +1 , and then declines and becomes negative on day +5 . The OLR anomaly on day 0 is noted to be slightly smaller than that on the adjoining two days, which may be influenced by the few events occurring outside the key region (see break definitions in section 3). The break period corresponds to the dry phases of the two intraseasonal components. Specifically, on day 0, the amplitudes of 10-25day (blue line) and 30-60-day (red line) oscillations explain $49.6 \%$ and $37.5 \%$ of the original suppression of convection, respectively. The 10-25-day oscillation shows a more transient evolution, with nadirs appearing on days -8 and +7 , which 


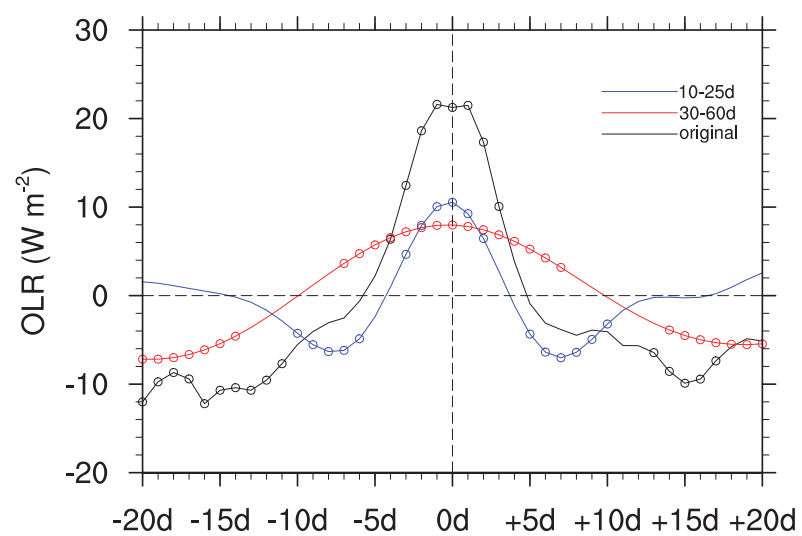

FIG. 7. Composite evolution of area-mean OLR anomalies $\left(\mathrm{W} \mathrm{m}^{-2}\right)$ over the key region from days -20 to +20 . Day 0 is designated as the peak day of each break event. The original anomalies and the 10-20-day and 30-60-day components are represented by black, blue, and red lines, respectively. Circles denote the anomalies significant at the $95 \%$ confidence level based on Student's $t$ test.

result in the phase transition of OLR around the break. In contrast, the 30-60-day component shows a slower evolution and maintains a significant positive phase from days -7 to +7 , steadily supporting the establishment and persistence of the monsoon break.

Figure 8 shows the spatial evolution of OLR anomalies. For the original anomalies (Figs. 8a-e), negative anomalies are observed over the key region and to the north of the Philippines at day -8 , when a band of positive anomalies extends from the South China Sea to the equatorial western Pacific. In the subsequent days, the positive anomalies over the equatorial western Pacific propagate northwestward and gradually enhance, while the negative anomalies become insignificant. On day 0 , the key region is occupied by positive anomalies that show a maximum amplitude greater than $30 \mathrm{~W} \mathrm{~m}^{-2}$, indicating a considerable suppression of convection. Afterward, the positive anomalies begin to weaken and move continually northwestward, showing a band structure with a northeast-southwest tilt. To the southeast, negative anomalies develop and cover the key region on day +8 .

The evolution of 10-25-day anomalies shows some similarities with that of the original anomalies, except that the spatial scale is smaller and the negative anomalies are more significant in the entire period (Figs. 8f-j). Due to the quasibiweekly period, the pattern on day 0 is almost the opposite of that on day -8 . Specifically, positive (negative) anomalies are generated over the equatorial western Pacific on day -8 (0) and then migrate northwestward, entering the key region and contributing to the monsoon break (recovery) on day $0(+8)$. The positive anomalies on day 0 are above $18 \mathrm{~W} \mathrm{~m}^{-2}$, accounting for $60 \%$ of the original maximum amplitude. These results confirm the crucial role of the 10-25-day oscillation in modulating the convection variation related to the break.
In contrast, the 30-60-day component shows persistent positive anomalies over the WNP that move slowly northwestward from days -8 to +8 (Figs. $8 \mathrm{k}-\mathrm{o}$ ). On day 0 , the 30-60-day positive anomalies exhibit a center of $>9 \mathrm{~W} \mathrm{~m}^{-2}$, smaller than that of the 10-25-day component. However, as early as day -4 , the significant positive anomalies have covered most of the key region and thus promoted the onset of the monsoon break. Likewise, the positive anomalies remain significant on day +4 , which delays the transition of convection from the inactive to the active phase.

Figure 9 shows the composite evolution of the $850-\mathrm{hPa}$ circulation anomaly. For the original anomaly (Figs. 9a-e), on day -8 , a cyclone is centered north of the Philippines, and a weak extensive anticyclone appears to its southeast, corresponding to the dipole pattern of convection anomalies (Fig. 8a). The anomalous anticyclone gradually shifts northwestward and becomes significant on day -4 . On day 0 , it arrives to the northwest of the key region and further intensifies, spanning approximately $60^{\circ}$ of longitude $\left(85^{\circ}-145^{\circ} \mathrm{E}\right)$ and $30^{\circ}$ of latitude $\left(0^{\circ}-30^{\circ} \mathrm{N}\right)$, becoming the dominant feature over the WNP. Affected by the anomalous northeasterlies related to the anticyclonic anomaly, convection over the key region is significantly suppressed (Fig. 8c). Afterward, a cyclonic anomaly appears to the southeast of the anticyclonic anomaly on day +4 . The cyclonic anomaly marches toward the northwest and dominates the key region on day +8 , at which time the convection turns to enhance again (Fig. 8e).

For the 10-25-day circulation anomaly (Figs. 9f-j), on day -8 , a cyclone near the Philippines and an anticyclone to its southeast form a clear wave train structure, which resembles the original anomaly. This wave train moves northwestward, with the cyclone gradually decaying. On day 0, the anticyclonic anomaly is substantially intensified, showing a horizontal scale comparable to the original anticyclone, which further confirms the large contribution of the 10-25-day oscillation to the monsoon break. Meanwhile, a new cyclonic anomaly is generated in the equatorial western Pacific that reaches the key region on day +8 . This alternating dominance of the anticyclone and cyclone over the WNP causes convection fluctuations around the monsoon break.

In contrast, the 30-60-day circulation anomaly (Figs. 9k-o) exhibits a stable anticyclone, which strengthens before day 0 and weakens afterward, featuring slow northwestward migration. These characteristics are consistent with those of suppressed convection (Figs. $8 \mathrm{k}-\mathrm{o}$ ). The anomalous anticyclone corresponds to the climatological monsoon trough (Fig. 1), contributing to weakening the monsoon trough, which is not conducive to convection development. Therefore, the prolonged dominance of the 30-60-day anticyclone provides a favorable background for the establishment and maintenance of the monsoon break.

Figure 10 illustrates more clearly the propagation of anomalous convection by showing OLR anomalies along the dashed line in Fig. 8a. Similarities can be found between the original and 10-25-day anomalies (Figs. 10a,b). Both of them feature alternating positive and negative centers along the path. The positive anomalies responsible for the break originate from the equatorial region and then move 


\section{original}

(a)-8d

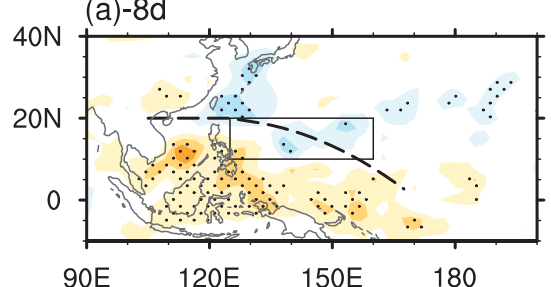

$90 \mathrm{E}$ (b) $-4 \mathrm{~d}$
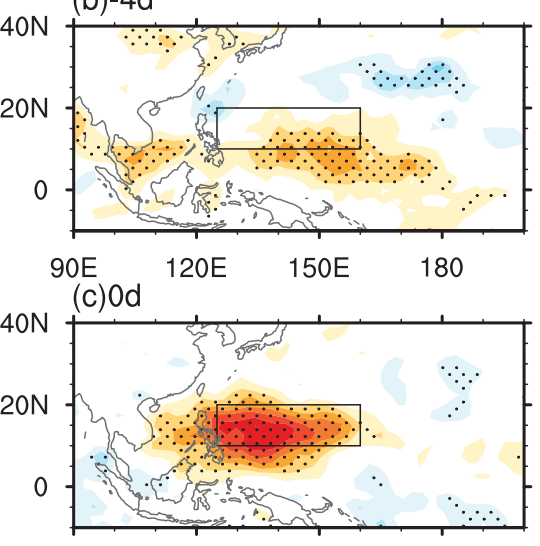

$90 \mathrm{E} \quad 120 \mathrm{E} \quad 150 \mathrm{E} \quad 180$

(d) $+4 d$
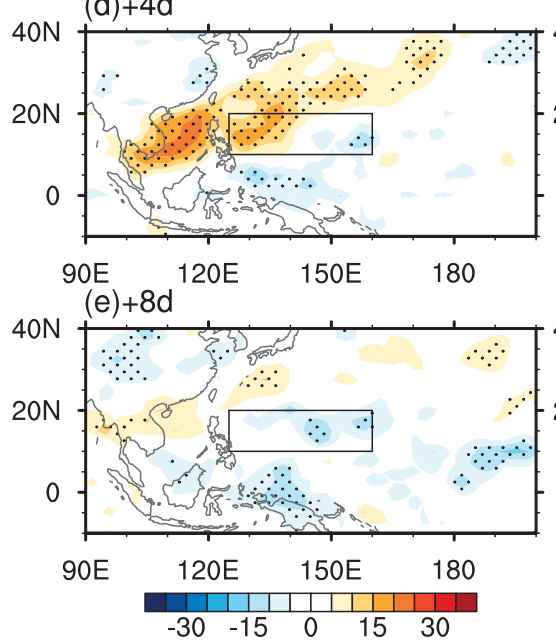

$10-25 d$ (f)-8d

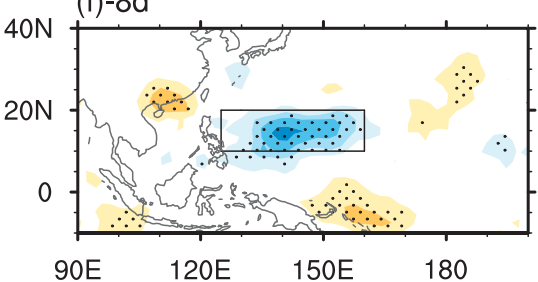

(g) $-4 d$

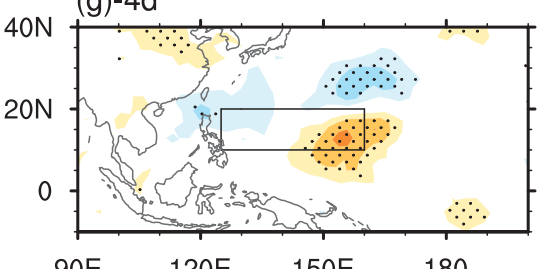

$90 \mathrm{E} \quad 120 \mathrm{E} \quad 150 \mathrm{E} \quad 180$
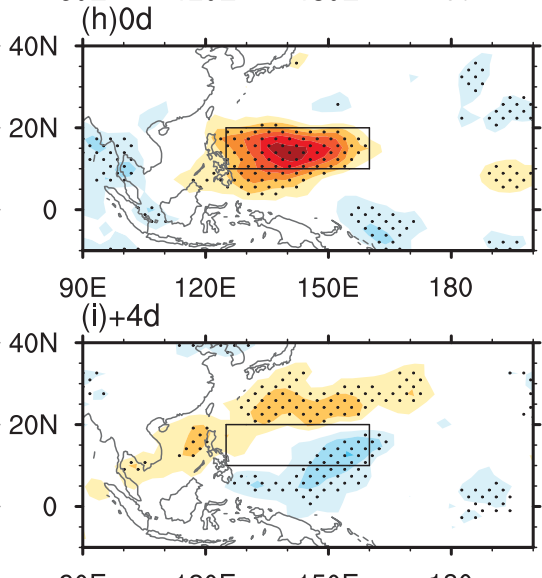

$90 \mathrm{E} \quad 120 \mathrm{E} \quad 150 \mathrm{E} \quad 180$

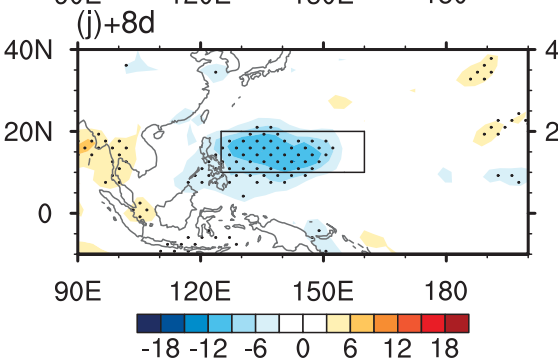

$30-60 d$

(k)-8d

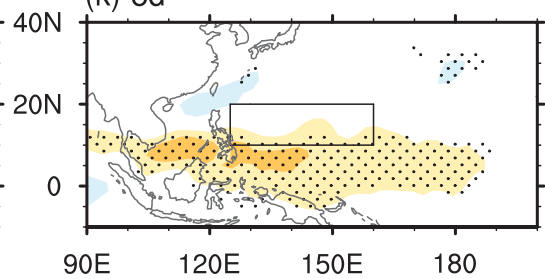

(I) $-4 d$

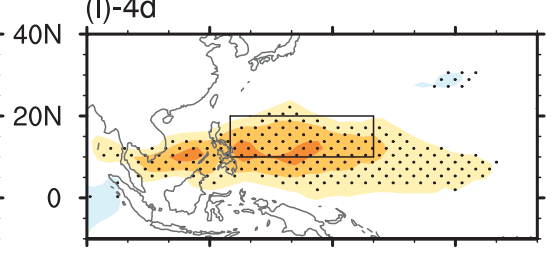

$90 \mathrm{E} \quad 120 \mathrm{E} \quad 150 \mathrm{E} \quad 180$ (m) $0 \mathrm{~d}$

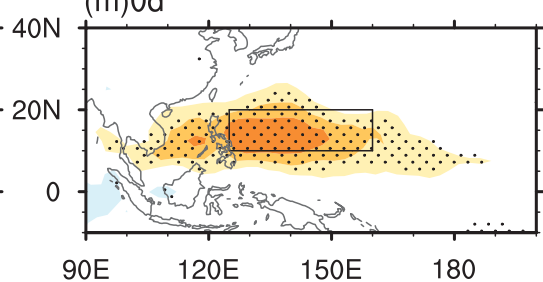

$(n)+4 d$

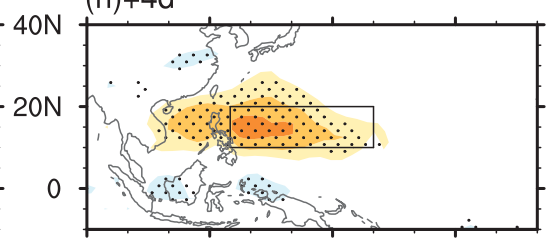

$90 \mathrm{E} \quad 120 \mathrm{E} \quad 150 \mathrm{E} \quad 180$ (0) $+8 d$

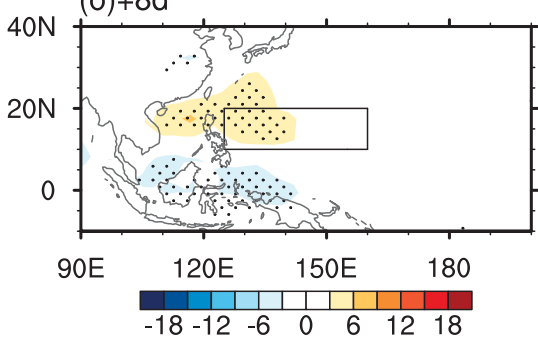

FIG. 8. Composite evolution of OLR anomalies $\left(\mathrm{W} \mathrm{m}^{-2}\right.$ ) from days -8 to +8 with an interval of 4 days. (a)-(e) Original OLR anomaly, (f)-(j) the 10-25-day filtered component, and (k)-(o) the 30-60-day filtered component. Stippled regions indicate the $90 \%$ confidence level based on Student's $t$ test. The dashed line in (a) represents the general propagation path of anomalous convection, which is used in Fig. 10. Rectangles denote the key region of the break.

northwestward. From days -4 to 0 , the positive anomalies intensify considerably with a faster westward propagation than before. This characteristic is more evident for the 10-25-day oscillation. Afterward, the positive anomalies continue to move northwestward and then westward to the South China Sea. Simultaneously, negative anomalies from the tropics strengthen and occupy the key region on day +8 . Compared with the 10-25-day oscillation, the 30-60-day oscillation shows a larger horizontal scale and slower northwestward propagation speed (Fig. 10c). The positive anomalies form over the equatorial western Pacific as early as day -12 and steadily occupy the key region from days -6 to +6 . The northwestward propagation of these break-related 10-25- and 30-60-day oscillations over the WNP is consistent with previous studies (e.g., Hsu and Weng 2001; Ko and Hsu 2006; Chen and Sui 2010; Li and Zhou 2013; Jia and Yang 2013; Chen et al. 2015; Li and Mao 2019).

The composite results (Figs. 7-10) indicate that the monsoon break occurs in dry (or inactive) phases of 10-25- and 
original

(a)-8d

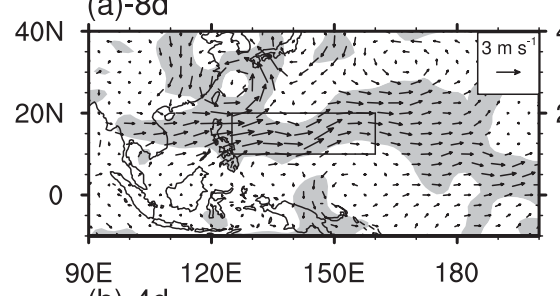

(b) $-4 d$
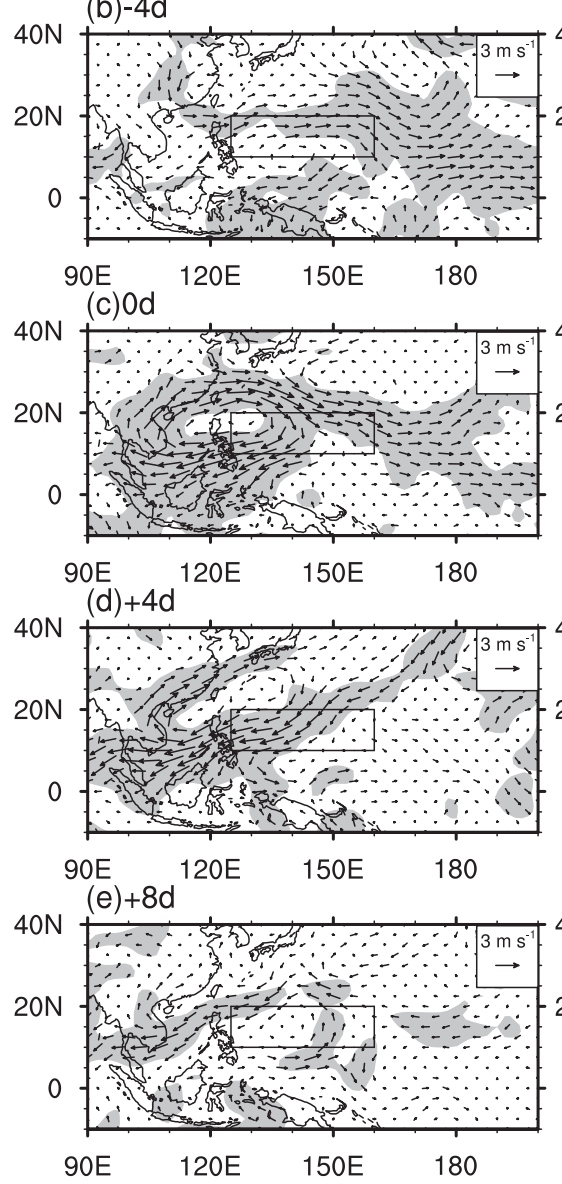

$10-25 d$

(f) $-8 \mathrm{~d}$

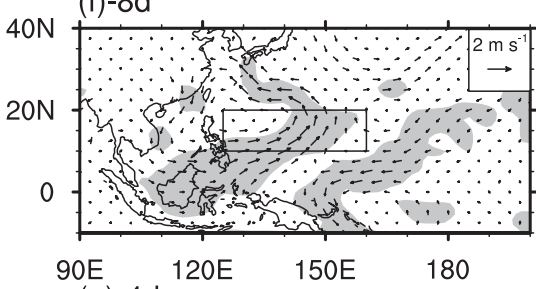

(g) $-4 d$

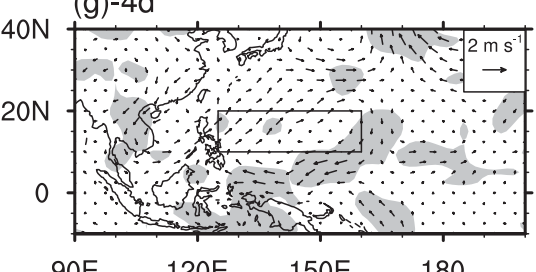

$90 \mathrm{E}$

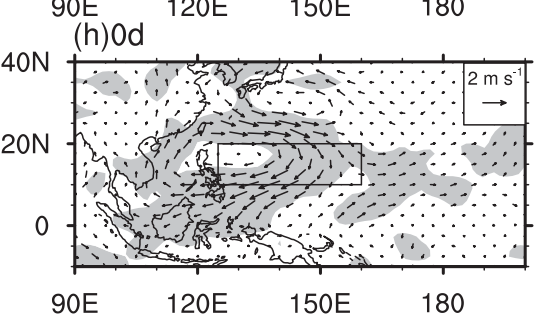

$\begin{array}{lll}90 \mathrm{E} & 120 \mathrm{E} \quad 150 \mathrm{E} \quad 180 \\ (\mathrm{i})+4 \mathrm{~d} & & \end{array}$

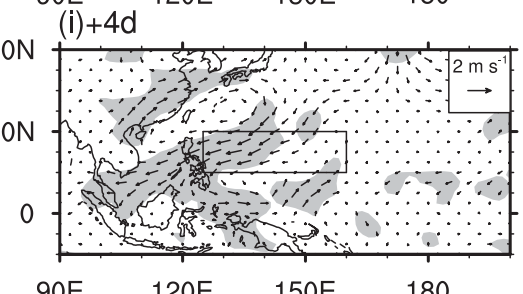

$90 \mathrm{E}$

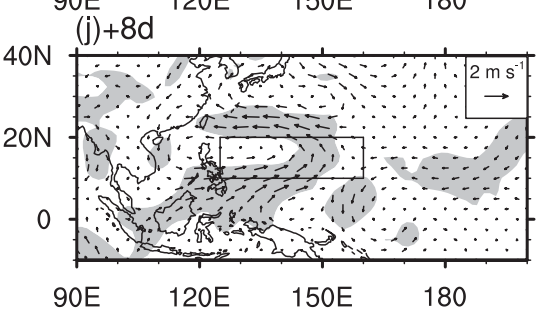

$30-60 d$

$(k)-8 d$
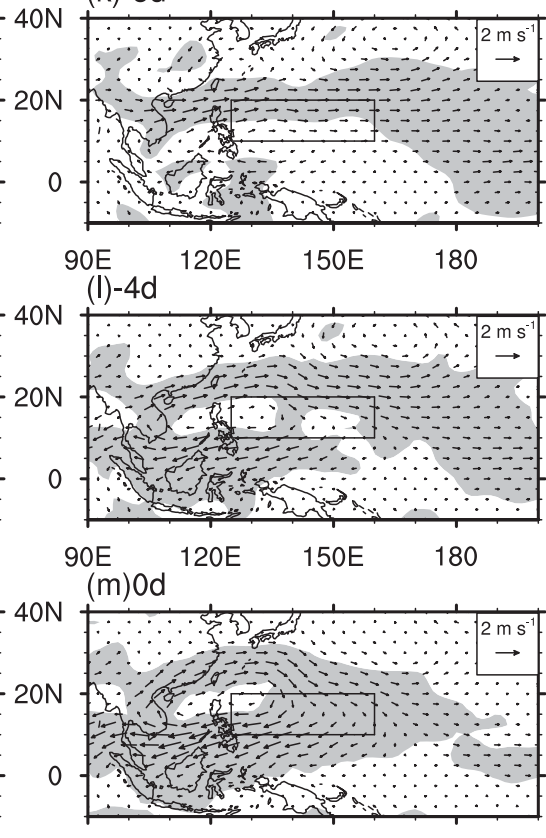

90E $120 \mathrm{E} \quad 150 \mathrm{E} \quad 180$ (n) $+4 d$

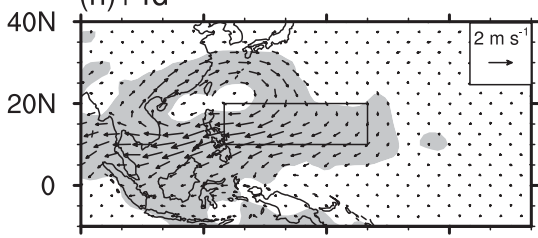

90E 120E 150E 180

(o) $+8 d$

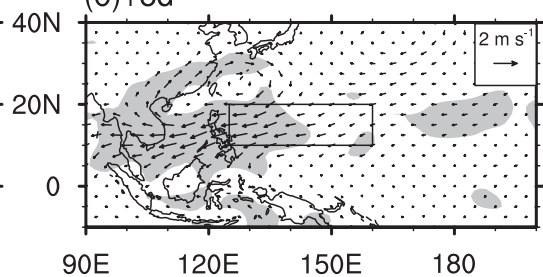

FIG. 9. As in Fig. 8, but for the 850-hPa wind anomalies $\left(\mathrm{m} \mathrm{s}^{-1}\right)$. Shading indicates the $90 \%$ confidence level based on Student's $t$ test.

30-60-day oscillations. To further verify this conclusion, we diagnosed the activity of the two ISOs for each break event. The life cycles of the two ISOs are both separated into eight phases (see the inset in Fig. 11a), with centers of each phase being the same as in previous studies (Chan et al. 2002; Fujinami and Yasunari 2004; Mao and Chan 2005; Yang et al. 2014; Gao et al. 2018). Specifically, phase 3 is the peak dry period, and phase 7 is the peak wet period. Phases 1 and 5 are the transitions from wet to dry periods and from dry to wet periods, respectively. Phases 2, 4, 6, and 8 are the periods between the transition and peak phases.

Figure 11 shows the frequency distribution of break events in eight phases of the two ISOs. For both ISOs, break events occur more frequently in dry phases than in wet phases, which is consistent with the composite results, demonstrating that the phases of the two ISOs can significantly modulate the occurrence of monsoon breaks. In particular, more than half of the events are concentrated in the peak dry phase (phase 3 ) for both the 10-25-day oscillation (36 events; 59\%) and the 30-60-day oscillation (31 events; 51\%). Nevertheless, differences can be found in the frequency distribution of break events between the two ISOs. For the 10-25-day oscillation, break events are almost evenly distributed in the remaining phases. Note that the number of break events in weak dry phases (phases 2 and 4) is identical to that in wet phases (phases 6-8). In contrast, for the 30-60-day oscillation, break 
(a) original

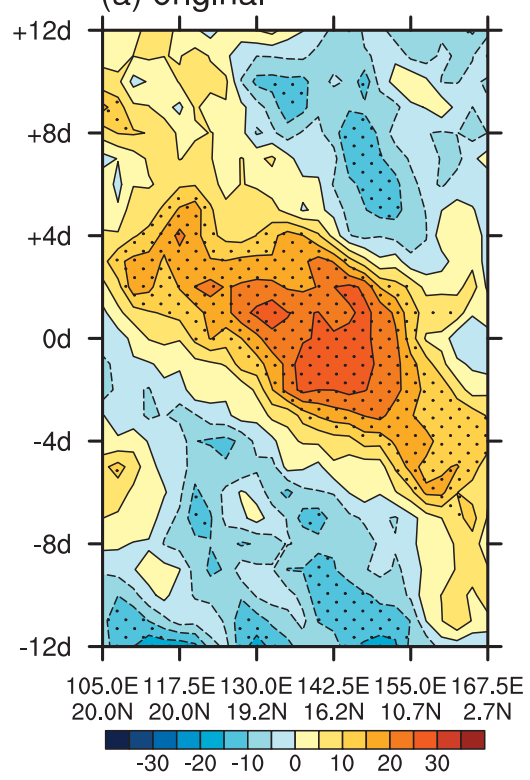

(b) $10-25 d$

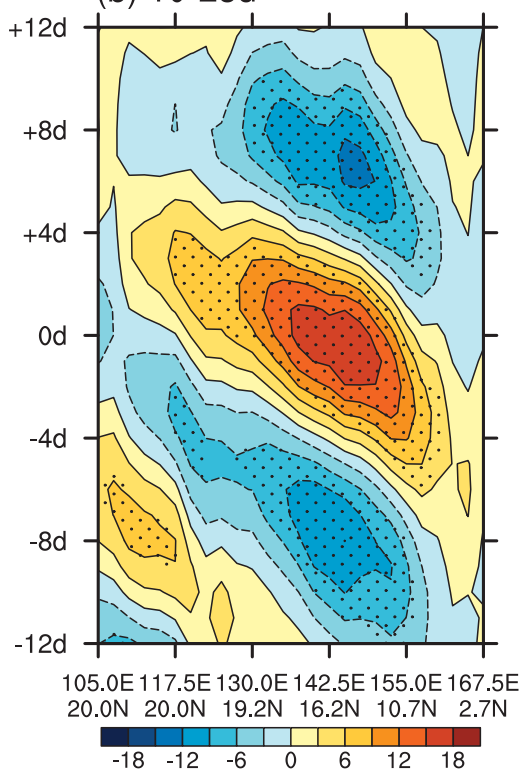

(c) 30-60d

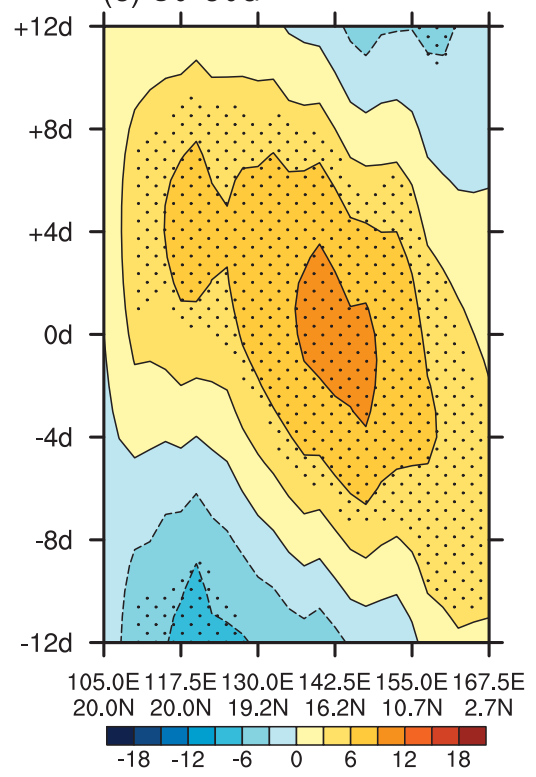

FIG. 10. Evolution of the composite (a) original, (b) 10-25-day, and (c) 30-60-day OLR anomalies (W m ${ }^{-2}$ ) along the dashed line shown in Fig. 8a. Stippled regions indicate the 90\% confidence level based on Student's $t$ test.

events are much more likely to occur in weak dry phases than in wet phases, with the number of events in the former 5 times that in the latter. That is, the monsoon break shows an intense preference for the peak dry phase of the two ISOs. For other phases, the modulation on the break is more significant by the 30-60-day oscillation than by the 10-25-day oscillation.

The above analysis reveals the relationship between the monsoon break and each single ISO. To illustrate the two ISO effects on the break more clearly, we examined the frequency distribution of break events in joint phases of 10-25and 30-60-day oscillations (Fig. 12). This shows that for each phase of the 10-25-day (30-60-day) oscillation, the occurrence frequency of break events is significantly higher in dry phases of the 30-60-day (10-25-day) oscillation than in the transition and wet phases, which confirms that the phase modulation of the 30-60-day (10-25-day) oscillation on the break is robust. Particularly, when the two ISOs are concurrently in the peak dry phase, break events reach the highest frequency of 17 events, accounting for $28 \%$ of all events. In contrast, no break events occur in simultaneous wet phases. Moreover, it is noted that events in dry phases of one ISO correspond to a spread phase distribution of the other ISO, while the rest of the events, especially those in wet phases, are concentrated in dry phases of the other ISO. This configuration between the two ISOs further demonstrates that they are the crucial factors leading to the monsoon break. In addition, the difference between the two ISOs can also be identified. For each phase of the 10-25-day (30-60-day) oscillation, the number of break events in weak dry phases of the 30-60-day (10-25-day) oscillation is more (comparable to or even less) than that in wet phases, which is consistent with the results in Fig. 11.

\section{Conclusions}

Based on 40 years of data from 1979 to 2018, this study identified all break events by examining the evolution of the summer monsoon year by year within the WNP domain $\left(0^{\circ}-25^{\circ} \mathrm{N}, 120^{\circ}-170^{\circ} \mathrm{E}\right)$. The statistical characteristics of these break events and the large-scale circulation and convection changes during the monsoon break were investigated. Furthermore, the monsoon break was found to be closely related to two dominant ISOs (i.e., 10-25- and 30-60-day oscillations). Therefore, the modulation of the monsoon break by the two ISOs was further explored.

A total of 61 break events were obtained among the 40 years, including 371 break days. These break events are concentrated in July-September over $10^{\circ}-20^{\circ} \mathrm{N}, 125^{\circ}-160^{\circ} \mathrm{E}$ (the so-called key region of the break in this study). The peak frequency appears at the end of August, when more than a quarter of the years experienced a break. This intensive occurrence of breaks may contribute to distinct suppression of convection in climatology, manifested by an increase of over $15 \mathrm{~W} \mathrm{~m}^{-2}$ in OLR from mid-August to early September. These break events have an average duration of 6.1 days. The occurrence frequency of break events decreases as the duration increases, with $74 \%$ falling in a short persistence of 3-7 days and merely $26 \%$ lasting longer (8-15 days). On the other hand, the intensity of break events varies from 245 to $275 \mathrm{~W} \mathrm{~m}^{-2}$, and the highest frequency occurs between 255 and $260 \mathrm{~W} \mathrm{~m}^{-2}$, which is $25-30 \mathrm{~W} \mathrm{~m}^{-2}$ higher than the OLR threshold $\left(230 \mathrm{~W} \mathrm{~m}^{-2}\right)$ used to define monsoon convection.

The monsoon break features significant variation in convection. Enhanced convection is detected over the key region before and after the break. In contrast, during the break, convection is significantly suppressed, with OLR anomaly 
(a) Phase of 10-25-day oscillation

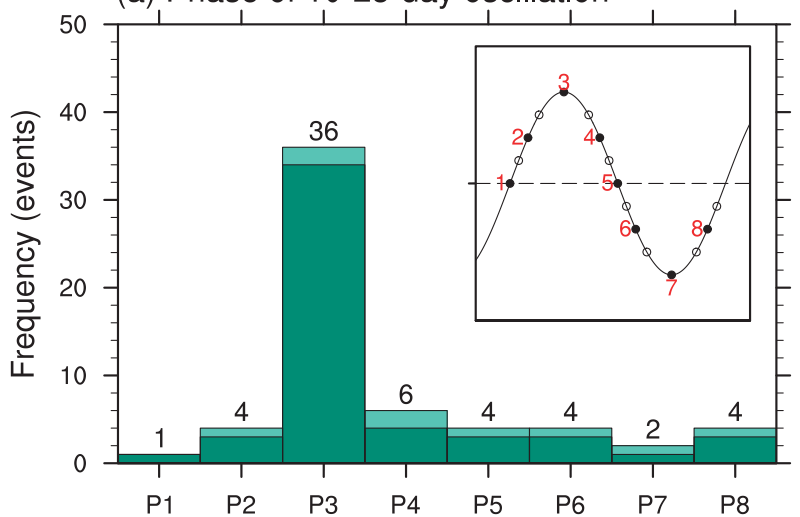

(b) Phase of 30-60-day oscillation

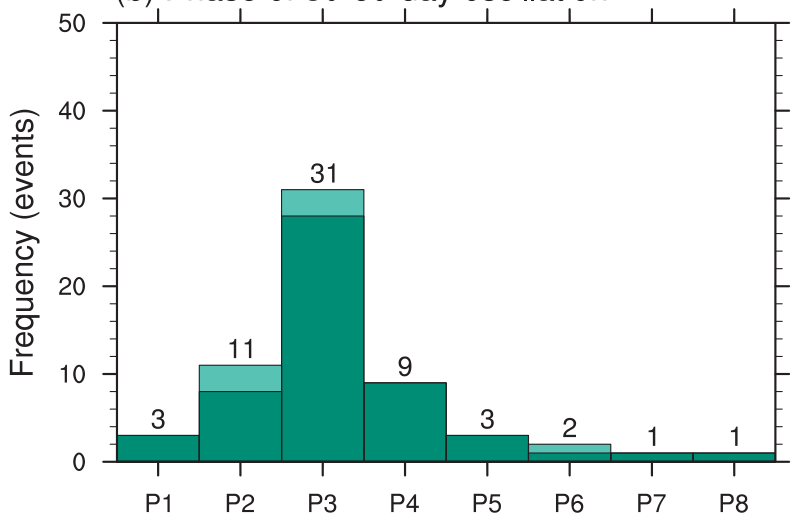

FIG. 11. Frequency of break events in eight phases of (a) 10-25and (b) 30-60-day oscillations. Light green indicates total events (numbers are shown above each bar), and dark green denotes events occurring in strong oscillations with amplitudes exceeding one standard deviation. The inset in (a) illustrates the phase partition of oscillations [The black dots represent the center of each phase (maximum for phase 3, minimum for phase 7, 0 for phases 1 and 5, half of the maximum for phases 2 and 4 , and half of the minimum for phases 6 and 8). The hollow circles correspond to the average values between two centers, which separate the two adjacent phases].

amplitudes $>30 \mathrm{~W} \mathrm{~m}^{-2}$. This convection variation is closely related to large-scale circulation changes. In the lower troposphere, the cyclonic anomalies in adjoining periods are replaced by an extensive anticyclonic anomaly during the break. This anomalous anticyclone corresponds to a noticeable westward retreat of the monsoon trough and a southwestward shift of the WPSH, with the latter covering a large extent of the key region. Meanwhile, the northeasterlies and divergence associated with the anticyclonic anomaly reduce the moisture inflow into the key region, thus inhibiting convection development. Moreover, an anomalous cyclone and convergence appear in the upper troposphere, which may be associated with a strong northward cross-equatorial flow along $100^{\circ}-150^{\circ} \mathrm{E}$, also favoring suppression of convection.

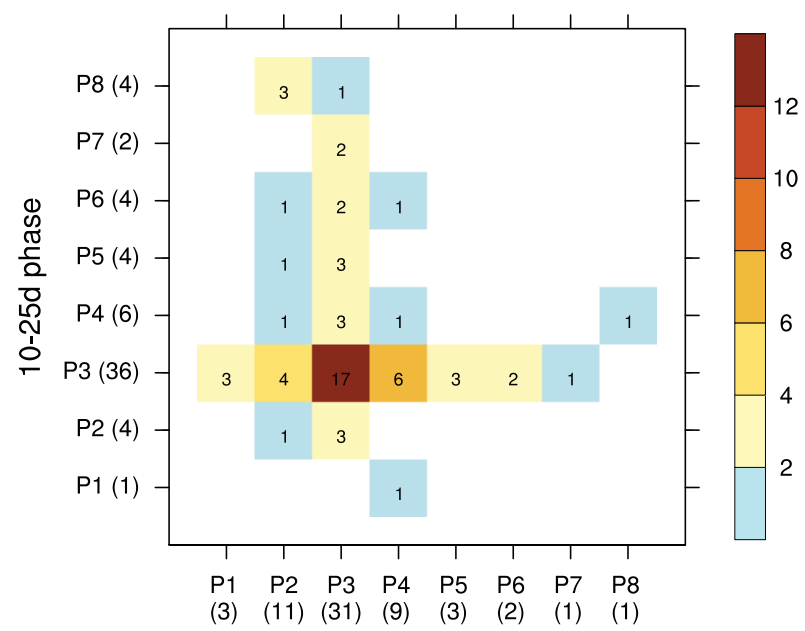

30-60d phase

FIG. 12. Frequency of break events in the joint phases of 10-25and 30-60-day oscillations. The numbers in parentheses on the $y$ axis ( $x$ axis) indicate the frequency of break events in each phase of the 10-25-day (30-60-day) oscillation.

The composite results indicate that the 10-25- and 30-60-day oscillations are two crucial factors that contribute to the monsoon break. The break period corresponds to dry phases of both oscillations, whose amplitudes account for $49.6 \%$ and $37.5 \%$ of the original suppression of convection, respectively. However, the roles of the two ISOs have some differences. Specifically, the alternation of the wet and dry phases (cyclone and anticyclone) of the 10-25-day oscillation results in convection fluctuation around the break, while the 30-60-day oscillation persists in a dry phase (anticyclone) before and after the break, steadily favoring the establishment and maintenance of the break. These two ISOs associated with the break both originate from the equatorial western Pacific, propagating northwestward and intensifying before dominating the WNPSM domain. A case-by-case diagnosis was performed to verify the relationship between the break and the two ISOs. For both ISOs, break events occur more frequently in dry phases, especially the peak dry phase, than in the transition and wet phases. Moreover, the frequency distribution of break events in joint phases of 10-25- and 30-60-day oscillations was investigated, and the configuration between the two ISOs further confirms that they are the major contributors to the monsoon break.

Since most break events are caused by 10-25- and 30-60day oscillations, the year-to-year difference of the break should arise from the interannual variation of the two ISOs. Many previous studies have emphasized the roles of ENSO in modulating ISO over the WNP. It was found that ISO tends to be intensified in El Niño developing summers due to increased easterly vertical shear and moisture conditions (Teng and Wang 2003; Deng and Li 2016). However, Lin and $\mathrm{Li}$ (2008) argued that the change in ISO intensity is more significant in ENSO decaying summers than in developing 
summers. In addition to ISO intensity, Liu et al. (2016) proposed that ENSO can regulate ISO periodicity. $\mathrm{Wu}$ and Cao (2017) further indicated that the impacts of ENSO on the two intraseasonal components are different: the quasi-biweekly oscillation is enhanced in El Niño developing summers, whereas the 30-60-day oscillation is enhanced in La Niña decaying summers. These studies imply that the interannual variation in ISOs and their relationships with ENSO are intricate. Whether and how ENSO affects the WNPSM break by modulating the two ISOs is an issue worthy of exploration in the future.

This study conducted a statistical analysis of break events during 1979-2018. However, evident differences can be found between individual events in their properties (Figs. 3 and 4) and relationships with ISOs (Figs. 11 and 12). This diversity of the monsoon break suggests the complicacy of the WNPSM's subseasonal variability, which will be investigated in our subsequent work. In addition, the climate impact of the monsoon break is an interesting topic worth further study. The anomalous convection and circulation related to the break seem to affect the summer monsoon over the South China Sea and Indochina Peninsula (Figs. 8-10). Also of concern is whether the break of the WNPSM can influence the East Asian summer monsoon. The East Asian monsoon rainband is greatly regulated by the position of the WPSH, which shows noticeable changes around the break (Fig. 6). Moreover, other factors may also play a role in inducing the break in addition to tropical ISOs. For instance, the WNPSM break in early August was suggested to be associated with midlatitude wave trains over the Eurasian continent and North Pacific (Xu and $\mathrm{Lu}$ 2016). Further exploration of the crucial factors leading to the monsoon break is necessary to comprehensively understand the mechanisms of the monsoon break.

Acknowledgments. The authors greatly appreciate the comments from two anonymous reviewers. This work was supported by the National Natural Science Foundation of China (Grants 41805064 and 41721004).

\section{REFERENCES}

Annamalai, H., and J. M. Slingo, 2001: Active/break cycles: Diagnosis of the intraseasonal variability of the Asian summer monsoon. Climate Dyn., 18, 85-102, https://doi.org/10.1007/ s003820100161.

Chan, J. C. L., W. Ai, and J. Xu, 2002: Mechanisms responsible for the maintenance of the 1998 South China Sea summer monsoon. J. Meteor. Soc. Japan, 80, 1103-1113, https://doi. org/10.2151/jmsj.80.1103.

Chen, G., and C.-H. Sui, 2010: Characteristics and origin of quasibiweekly oscillation over the western North Pacific during boreal summer. J. Geophys. Res., 115, D14113, https://doi. org/10.1029/2009JD013389.

Chen, J., Z. Wen, R. Wu, Z. Chen, and P. Zhao, 2015: Influences of northward propagating 25-90-day and quasi-biweekly oscillations on eastern China summer rainfall. Climate Dyn., 45, 105-124, https://doi.org/10.1007/s00382-014-2334-y.

Chen, T.-C., and J.-M. Chen, 1995: An observational study of the South China Sea monsoon during the 1979 summer: Onset and life cycle. Mon. Wea. Rev., 123, 2295-2318, https://doi. org/10.1175/1520-0493(1995)123<2295:AOSOTS > 2.0.CO;2.

De, U. S., R. R. Lele, and J. C. Natu, 1998: Breaks in southwest monsoon. India Meteorological Department Rep. 1998/3, $24 \mathrm{pp}$.

—, R. K. Dube, and G. S. P. Rao, 2005: Extreme weather events over India in the last 100 years. J. Ind. Geophys. Union, 9, 173-187.

Deng, L., and T. Li, 2016: Relative roles of background moisture and vertical shear in regulating interannual variability of boreal summer intraseasonal oscillations. J. Climate, 29, 7009-7025, https://doi.org/10.1175/JCLI-D-15-0498.1.

Fujinami, H., and T. Yasunari, 2004: Submonthly variability of convection and circulation over and around the Tibetan Plateau during the boreal summer. J. Meteor. Soc. Japan, 82, 1545-1564, https://doi.org/10.2151/jmsj.82.1545.

Gadgil, S., and P. V. Joseph, 2003: On breaks of the Indian monsoon. J. Earth Syst. Sci., 112, 529-558, https://doi.org/10.1007/ BF02709778.

Gao, M., J. Yang, B. Wang, S. Zhou, D. Gong, and S.-J. Kim, 2018: How are heat waves over Yangtze River valley associated with atmospheric quasi-biweekly oscillation? Climate Dyn., 51, 4421-4437, https://doi.org/10.1007/s00382-017-3526-z.

Gill, A. E., 1980: Some simple solutions for heat-induced tropical circulation. Quart. J. Roy. Meteor. Soc., 106, 447-462, https:// doi.org/10.1002/qj.49710644905.

Goswami, B. N., and R. S. Ajayamohan, 2001: Intraseasonal oscillations and interannual variability of the Indian summer monsoon. J. Climate, 14, 1180-1198, https://doi.org/10.1175/15200442(2001)014<1180:IOAIVO>2.0.CO;2.

Hsu, H.-H., and C.-H. Weng, 2001: Northwestward propagation of the intraseasonal oscillation in the western North Pacific during the boreal summer: Structure and mechanism. J. Climate, 14, 3834-3850, https://doi.org/10.1175/1520-0442(2001) 014<3834:NPOTIO $>2.0 . \mathrm{CO} ; 2$.

Jia, X., and S. Yang, 2013: Impact of the quasi-biweekly oscillation over the western North Pacific on East Asian subtropical monsoon during early summer. J. Geophys. Res. Atmos., 118, 4421-4434, https://doi.org/10.1002/jgrd.50422.

Kanamitsu, M., W. Ebisuzaki, J. Woollen, S.-K. Yang, J. Hnilo, M. Fiorino, and G. Potter, 2002: NCEP-DOE AMIP-II reanalysis (R-2). Bull. Amer. Meteor. Soc., 83, 1631-1644, https:// doi.org/10.1175/BAMS-83-11-1631.

Ko, K.-C., and H.-H. Hsu, 2006: Sub-monthly circulation features associated with tropical cyclone tracks over the East Asian monsoon area during July-August season. J. Meteor. Soc. Japan, 84, 871-889, https://doi.org/10.2151/jmsj.84.871.

Krishnamurti, T. N., and P. Ardanuy, 1980: The 10 to 20-day westward propagating mode and "breaks in the monsoons". Tellus, 32, 15-26, https://doi.org/10.3402/tellusa.v32i1.10476.

Krishnan, R., C. Zhang, and M. Sugi, 2000: Dynamics of breaks in the Indian summer monsoon. J. Atmos. Sci., 57, 1354-1372, https://doi.org/10.1175/1520-0469(2000)057<1354:DOBITI $>2$. $0 . \mathrm{CO} ; 2$.

Lee, J.-Y., B. Wang, M. C. Wheeler, X. Fu, D. E. Waliser, and I.-S. Kang, 2013: Real-time multivariate indices for the boreal summer intraseasonal oscillation over the Asian summer monsoon region. Climate Dyn., 40, 493-509, https://doi.org/ 10.1007/s00382-012-1544-4.

Li, J., and J. Mao, 2019: Factors controlling the interannual variation of 30-60-day boreal summer intraseasonal oscillation over the Asian summer monsoon region. Climate Dyn., 52, 1651-1672, https://doi.org/10.1007/s00382-018-4216-1. 
Li, R. C. Y., and W. Zhou, 2013: Modulation of western North Pacific tropical cyclone activity by the ISO. Part I: Genesis and intensity. J. Climate, 26, 2904-2918, https://doi.org/10. 1175/JCLI-D-12-00210.1.

Liebmann, B., and C. A. Smith, 1996: Description of a complete (interpolated) outgoing longwave radiation dataset. Bull. Amer. Meteor. Soc., 77, 1275-1277, https://doi.org/10.1175/ 1520-0477-77.6.1274.

Lin, A., and T. Li, 2008: Energy spectrum characteristics of boreal summer intraseasonal oscillations: Climatology and variations during the ENSO developing and decaying phases. J. Climate, 21, 6304-6320, https://doi.org/10.1175/2008JCLI2331.1.

LinHo, and B. Wang, 2002: The time-space structure of the Asian-Pacific summer monsoon: A fast annual cycle view. $J$. Climate, 15, 2001-2019, https://doi.org/10.1175/1520-0442 (2002)015<2001:TTSSOT>2.0.CO;2.

Liu, F., and B. Wang, 2014: A mechanism for explaining the maximum intraseasonal oscillation center over the western North Pacific. J. Climate, 27, 958-968, https://doi.org/10.1175/JCLID-12-00797.1.

— T. Li, H. Wang, L. Deng, and Y. Zhang, 2016: Modulation of boreal summer intraseasonal oscillations over the western North Pacific by ENSO. J. Climate, 29, 7189-7201, https://doi. org/10.1175/JCLI-D-15-0831.1.

Mandke, S. K., A. K. Sahai, M. A. Shinde, S. Joseph, and R. Chattopadhyay, 2007: Simulated changes in active/break spells during the Indian summer monsoon due to enhanced $\mathrm{CO}_{2}$ concentrations: Assessment from selected coupled atmosphere-ocean global climate models. Int. J. Climatol., 27, 837-859, https://doi.org/10.1002/joc.1440.

Mao, J., and J. C. L. Chan, 2005: Intraseasonal variability of the South China Sea summer monsoon. J. Climate, 18, 23882402, https://doi.org/10.1175/JCLI3395.1.

Nitta, T., 1987: Convective activities in the tropical western Pacific and their impact on the Northern Hemisphere summer circulation. J. Meteor. Soc. Japan, 65, 373-390, https://doi.org/10. 2151/jmsj1965.65.3_373.

Olaguera, L. M. P., J. Matsumoto, H. Kubota, E. O. Cayanan, and F. D. Hilario, 2021: A climatological analysis of the monsoon break following the summer monsoon onset over Luzon Island, Philippines. Int. J. Climatol., 41, 2100-2117, https://oi. org/10.1002/joc.6949.

Pai, D. S., L. Sridhar, and M. R. R. Kumar, 2016: Active and break events of Indian summer monsoon during 1901-2014. Climate Dyn., 46, 3921-3939, https://doi.org/10.1007/s00382015-2813-9.

Rajeevan, M., S. Gadgil, and J. Bhate, 2010: Active and break spells of the Indian summer monsoon. J. Earth Syst. Sci., 119, 229-247, https://doi.org/10.1007/s12040-010-0019-4.

Ramamurthy, K., 1969: Monsoon of India: Some aspects of the "break" in the Indian southwest monsoon during July and August. India Meteorological Department FMU Rep. IV-183, $13 \mathrm{pp}$.

Rao, Y. P., 1976: Southwest monsoon.. Indian Meteorological Department Monograph 1/1976, 367 pp.

Sardeshmukh, P. D., and B. J. Hoskins, 1985: Vorticity balances in the tropics during the 1982-83 El Niño-Southern Oscillation event. Quart. J. Roy. Meteor. Soc., 111, 261-278, https:// doi.org/10.1256/smsqj.46801.
Singh, M., and R. Bhatla, 2019: Modulation of active-break spell of Indian summer monsoon by Madden Julian Oscillation. $J$. Earth Syst. Sci., 128, 70, https://doi.org/10.1007/s12040-0191091-z.

Teng, H., and B. Wang, 2003: Interannual variations of the boreal summer intraseasonal oscillation in the Asian-Pacific region. J. Climate, 16, 3572-3584, https://doi.org/10.1175/15200442(2003)016<3572:IVOTBS>2.0.CO;2.

Ueda, H., T. Yasunari, and R. Kawamura, 1995: Abrupt seasonal change of large-scale convective activity over the western Pacific in the northern summer. J. Meteor. Soc. Japan, 73, 795-809, https://doi.org/10.2151/jmsj1965.73.4_795.

—, M. Ohba, and S.-P. Xie, 2009: Important factors for the development of the Asian-northwest Pacific summer monsoon. J. Climate, 22, 649-669, https://doi.org/10.1175/ 2008JCLI2341.1.

Vega, I., P. Ribera, and D. Gallego, 2020: Characteristics of the onset, withdrawal, and breaks of the western North Pacific summer monsoon in the 1949-2014 period. J. Climate, 33, 7371-7389, https://doi.org/10.1175/JCLI-D-19-0734.1.

Wang, B., and X. Xu, 1997: Northern Hemisphere summer monsoon singularities and climatological intraseasonal oscillation. J. Climate, 10, 1071-1085, https://doi.org/10.1175/15200442(1997)010<1071:NHSMSA > 2.0.CO;2.

— monsoon. J. Climate, 15, 386-398, https://doi.org/10.1175/ 1520-0442(2002)015<0386:RSOTAP > 2.0.CO;2.

Wang, H., Y. Ding, and J. He, 2005: The climate research of summer monsoon over the western North Pacific (in Chinese). Acta Meteor. Sin., 63, 418-430.

$\mathrm{Wu}, \mathrm{R} ., 2002$ : Processes for the northeastward advance of the summer monsoon over the western North Pacific. J. Meteor. Soc. Japan, 80, 67-83, https://doi.org/10.2151/jmsj.80.67.

— , and B. Wang, 2000: Interannual variability of summer monsoon onset over the western North Pacific and the underlying processes. J. Climate, 13, 2483-2501, https://doi.org/10.1175/ 1520-0442(2000)013<2483:IVOSMO > 2.0.CO;2.

— , and — 2001: Multi-stage onset of the summer monsoon over the western North Pacific. Climate Dyn., 17, 277-289, https://doi.org/10.1007/s003820000118.

— , and X. Cao, 2017: Relationship of boreal summer 10-20-day and 30-60-day intraseasonal oscillation intensity over the tropical western North Pacific to tropical Indo-Pacific SST. Climate Dyn., 48, 3529-3546, https://doi.org/10.1007/s00382016-3282-5.

$\mathrm{Xu}, \mathrm{K}$., and R. Lu, 2015: Break of the western North Pacific summer monsoon in early August. J. Climate, 28, 3420-3434, https://doi.org/10.1175/JCLI-D-14-00588.1.

, and - 2016: Change in tropical cyclone activity during the break of the western North Pacific summer monsoon in early August. J. Climate, 29, 2457-2469, https://doi.org/10. 1175/JCLI-D-15-0587.1.

,-- , B.-J. Kim, J. Mao, and J.-K. Park, 2019: Influence of tropical SSTs on the interannual variation of the summer monsoon break over the western North Pacific. J. Climate, 32, 2807-2821, https://doi.org/10.1175/JCLI-D-18-0282.1.

Yang, J., Q. Bao, B. Wang, D.-Y. Gong, H. He, and M.-N. Gao, 2014: Distinct quasi-biweekly features of the subtropical East Asian monsoon during early and late summers. Climate Dyn., 42, 1469-1486, https://doi.org/10.1007/s00382-013-1728-6. 